\title{
Subprime Mortgage Crisis and the Exchange Rate Channel: Evidence from Six Countries of the Zone Euro-Med
}

\author{
Ahmed Hachicha ${ }^{1}$, Fatma Hachicha ${ }^{2}$ \\ ${ }^{1}$ Department of Economic Development, Faculty of Economics and Management of Sfax, Sfax, Tunisia \\ ${ }^{2}$ Department of Finance, Institute of Higher Commercial Studies of Sfax, Tunisia \\ Email: ^hachicha.ahmed@fsegs.rnu.tn
}

How to cite this paper: Hachicha, A. and Hachicha, F. (2017) Subprime Mortgage Crisis and the Exchange Rate Channel: Evidence from Six Countries of the Zone Euro-Med. Applied Mathematics, 8, 1619-1647. https://doi.org/10.4236/am.2017.811118

Received: October 27, 2017

Accepted: November 25, 2017

Published: November 28, 2017

Copyright (c) 2017 by authors and Scientific Research Publishing Inc. This work is licensed under the Creative Commons Attribution International License (CC BY 4.0).

http://creativecommons.org/licenses/by/4.0/

\begin{abstract}
This article proposes to assess the impact of the subprime mortgage crisis on the exchange rate channel in 6 countries of the Euro-Med zone. To do this, our analysis is based on three evaluation methods that allow us to conclude that the exchange rate channel is better evaluated by the non-linear approach of the countries studied. Thus, the depreciation of the exchange rate adopted by the countries of the Med zone did worse macroeconomic stability and economic convergence.
\end{abstract}

\section{Keywords}

Subprime Mortgage Crisis, Exchange Rate Channel, Euro-Med Zone, Three Evaluation Methods, Economic Convergence

\section{Introduction}

The financial crisis of the subprime has shocked the whole world for almost seven years. The magnitude and urgency of this crisis have taken a few States across the world by surprise. In order to remedy the deterioration of the economic situation of not bad savings, some economies have taken precautionary measures by the adoption of macro prudential policies for economic recovery. In addition, it may also be noted the attempt to massive injection of funds to bail out the financial systems of some of the countries of the euro area.

Despite these attempts, a crisis of confidence without precedent shakes up to present the world economy. The international market is also marked by the financial globalization on the one hand and the debt crisis in the euro area. On the other hand, Greece was the first to dive in this crisis of the countries of the zone 
Med with trading partners of the euro area are found then in full crisis amplified by the possible repercussions of the Arab Spring.

The channel of the exchange rate and net exports of each country of the Euro-Med zone plays an important role in the way in which monetary policy affects the economy of each of the countries of the area. This has led us to question on the current situation of these economies. What is the impact of the crisis on the channel of the exchange rate? Are the effects of monetary policy well transmitted to the real sphere? What is the impact of this crisis on the most affected countries of the euro area to know the Greece, Italy, Spain and Portugal? What is also the impact on the countries of the zone Med the more vulnerable to the crisis, including that of Tunisia and Egypt?

Our work is developed in the purpose of trying to project on our article all the lights which he would agree starting in the first section by the estimation of a linear model for structural policies in order to study the impact of the crisis of the "subprime" on the channel of the exchange rate in a few countries of the Euro-Med zone.

The second section immerses us in the assessment of the magnitude of current misalignments of the exchange rate and the determination of the exchange rate behavioral our sample formed by 6 countries of the Euro-Med zone.

The third section considers a non-linear model to settings in the variables in the time in order to benefit from a more rigorous analysis of the impact of the crisis on the channel of the exchange rate in a context of financial instability.

\section{First Method of Evaluation}

Effects of the monetary policy differ from one country to another for various reasons. We are interested at the time of our research to identify specificities of the transmission channels of exchange rate of the monetary policy in the case of six countries of the zone Euro-Med like Tunisia, Egypt, Italy, Portugal, Greece and Spain.

\subsection{Identification of Structural Model VECM}

The models (VAR) became increasingly popular since the criticism of [1] brought to the approach of the simultaneous equations.

However, the form standard VAR is a reduced form of the model and the economic interpretation of the results is often impossible, unless the reduced form of the VAR dependent on the economic model.

When the economic theory provides a link between the errors envisaged and the fundamental shocks, the model which results from it calls a SVAR. However, the models of this kind are regarded as an important tool in the economy and are used to analyze certain effects by which we can quote the effects of the monetary shocks ([2] [3] [4]), effects of the technological shocks and effects of the tax shocks ([5]).

It is thus possible to offer the technique of the SVAR to the VECM with coin- 
tegrated variables and the relation between the structural and reduced form model VECM can be described as follows:

The analysis of the structural VECM begins starting from the reduced form of the standard model VAR (p)

$$
Y_{t}=A_{1} Y_{t-1}+\cdots+A_{p} Y_{t-p}+\Xi D_{t}+u_{t}
$$

where $Y_{t}$ is a vector of dimension $(K \times 1), D_{t}$ is a vector determinist term, and $A_{1}, A_{2}, \cdots, A_{p}$ are coefficients of a matrix of dimension $(K \times K) . \Xi$ is the coefficient of matrix associated under the deterministic terms, like the constant, the trend and the dummy variable. $u_{t}$ is the white noise.

The model VAR has a specific presentation of vector with correction of error noted by VECM (p).

$$
\Delta Y=\Pi Y_{t-1}+\Gamma_{1} \Delta Y_{t-1}+\cdots+\Gamma_{p-1} \Delta Y_{t-p+1}+\Xi D_{t}+u_{t}
$$

In the cointegrated models, $\Pi$ has a reduced rank which does not exceed $K$ and can be broken down as follows $\Pi=\alpha \beta^{\prime}$ where $\alpha$ and $\beta$ are two matrices containing the coefficients of adjustment of the vectors of cointegrated vectors are two matrices containing the coefficients for adjustment of dimension cointegration vectors of dimension $(K \times r)$.

We are interested in the effects of fundamental shock $\varepsilon_{t}$ in the system of variables $y_{t}$. These shocks can be expressed in term of structural VECM form.

$$
K \Delta Y_{t}=\Pi_{1} Y_{t-1}+\gamma_{1} \Delta Y_{t-1}+\cdots+\gamma_{p-1} \Delta Y_{t-p+1}+\Xi D_{t}+\varepsilon_{t}
$$

With $\varepsilon_{t}$ a vector of dimension $(K \times 1)$ containing the unobservable structural disorders and variance covariance $\Sigma_{\varepsilon}$. In order to quantify the responses to economic shocks $\varepsilon_{t}$, it must link errors in structural shocks $\varepsilon_{t}$.

Multiplying the above equation by $K^{-1}$, we get the reduced form with $\Gamma_{1}=K^{-1} \gamma_{1}, \cdots, \gamma_{p-1}=K^{-1} \gamma_{p-1} \Xi=K^{-1} \bar{\Xi}$ and $u_{t}=K^{-1} \varepsilon_{t}=A_{0} \varepsilon_{t}$. It will be more convenient to express the model in terms of contemporary impact matrix $A_{0}=K^{-1}$.

To analyze the effect of the structural shocks, we will need to identify $K^{2}$ the elements of $A_{0}$. Thus, we will have interest to identify the restrictions on economic theory. To do this, we use the following relationship:

$$
\Sigma_{u}=E\left(u_{t A} u_{t^{\prime}}\right)=A_{0} E\left(\varepsilon_{t} \varepsilon_{t^{\prime}}\right) A_{0}^{\prime}=A_{0} \Sigma_{\varepsilon} A_{0}^{\prime}
$$

The SVECM model can be used to identify shocks by imposing restrictions on the matrix $A$ of long term and the matrix $B$ of short term.

The matrix $B$ is as $u_{t}=B \varepsilon_{t}$ and long term matrix is as follows:

$$
\Xi=\beta_{\perp}\left(\alpha_{\perp}^{\prime}\left(I_{k}-\sum_{i=1}^{p-1} \Gamma_{i}\right) \beta \perp\right)^{-1} \alpha_{\perp}^{\prime}
$$

However, the shock $\varepsilon$ of long term effect is given by: $\Xi B$ of row $K-r$, $r k(\Xi)=K-r$. The matrix $\Xi B$ can have at most vectors $r$ column zero. However, we can have $r$ transitory shocks and at least $k^{\star}=(K-r)$ permanent shocks. Given the reduced matrix rank, each column zero vector is $K^{\star}$ independent re- 
strictions.

$K^{*}\left(K^{*}-1\right)$ additional restrictions are needed to identify the permanent shocks and $r(r-1) / 2$ additional restrictions to detect transitory shocks.

\subsection{Data Presentation and Processing}

In this paper, we are going to use a structural VECM model on monthly data from 2007 M6 till 2012 M8.

We estimate a model of six variables which includes two objective variables to know the index of production as a proxy of GDP and inflation, three key variables of transmission of the exchange rate channel and its determinants to know the real exchange rate, the export, import and the rate of the monetary market (TMM) variable key instrument of monetary policy. This model is re estimated to 6 times since we have a sample formed by 6 countries of the EuroMed zone namely Tunisia, Egypt, Italy, Portugal, Greece and Spain.

Data are taken of monthly frequencies converted into million dollars constant and a logarithmic transformation was applied to them. These variables were collected of the International Monetary Fund. Estimation was made by software J-Multi and results relating to this method are introduced in the Appendix A.

In fact, the structural approach has been extended nothing that to capture the maximum of information on the fluctuations of the actual variables reflecting the reality of the economies. In addition, the SVECM model can be used in the determination of the effect of monetary policy shocks as it is the case of this first section. The relevance of these models lies in the way to provide the economist the possibility to broaden the scope of observation of the fluctuations of actual data within an economic theory ([6]).

In order to determine the descriptive statistics, the autocorrelation and the order of integration of the series, several tests have been applied as the test portmanteau, Jarque Berra, ARCH-LM, ADF, Schmidt Perron. These confirm the strong clearly stipulating that all the series are integrated of order one, i.e., I (1).

The structure of identification and the imposition of restrictions are based on the different monetary criteria of each country and the various conditions econometric evidence.

To study the long-term relations between the variables, we have resorted to the two tests for cointegration to know the test of Johansen and Juselius and the test of Saikonnen and Lutkepohl. Consequently, like ([7]) or ([8]), we have chosen to conduct our estimates on the variables in level.

\subsection{Results of the Impulse Responses}

We are interested in a first time to identify the responses of objective variables, the exchange rate, exports and imports as a result of a shock of monetary policy. Subsequently, we observe the responses of a shock of the exchange rate on the whole of the variables of the model in order to detect the impact of the change in 
the exchange rate on the latter.

An overall look on the response functions of all the systems of the four countries of the euro area explored in Appendix A highlights some important lessons learned from Figures 1-10. First of all, if we rely on only estimates having recourse to the index of production, our estimates come in the whole confirm a result replied extensively in the literature, namely the modest contribution of the canal of the rate of interest. In a flexible exchange rate regime, the effects of the interest rate channel are amplified by the channel of the exchange rate because the increase in the rate of interest causes a real appreciation of the exchange rate harmful to the external competitiveness. It is essential to indicate that we use the exchange rate quoted to the uncertain, in other words: 1 dollar for our case for $\mathrm{Z}$ units of the currency of the country considered (TND, Egyptian Pounds or Euro).

Therefore, when the exchange rate is increasing (resp. decreases), this means that the currency of the country considered depreciates (resp. appreciates). On the other hand, and in a flexible exchange rate regime and with international mobility of capital, a decline in the rate of interest is translated, all things being equal, by a depreciation of the real effective exchange rate of the currency. This devaluation causes a drop in the prices of products intended for export, which increases the external demand and raises the local firms to produce more.

Our results are in agreement with [9], we find both in the short and the long-term a remarkable difference in the direction of variation and in the magnitude of the response of the output and the rate of inflation. These latest objective variables react with a magnitude more important for the Tunisian context only in the short term. The results are perfectly in perfect agreement with the work of Hachicha and Chaabane ([10] [11]), which according to the monthly data in a first opportunity and annual in a second prove that the channel of the exchange rate plays a role almost absent in the amplification of the actions of the monetary policy in the case of Tunisia. It is the channel that has a weak contribution of the macroeconomic stability of the Tunisian economy.

Nevertheless, the study of the impulse is not a simple thing to the extent where according to Mishkin ([12] [13]) production is in decline as a result of the decline in the investment.

These are the basic concepts of the macroeconomics traditional. However, [4] and [14] assert that the drop in the level of activity can lower or increase the demand for credit. [3] prove for the case of the Egypt that the effects of the channel of the interest rate and the credit are limited in time. It results in difficulties to deduct the sign of the variation of the investment, and this is not automatically a decline. What we have just to elucidate is part of those who speak of the macroeconomics New based on the foundations of the modern macroeconomics ([15]), but the observation of the effect mystery and amazing phenomenon affecting primarily the price is possible.

\section{The Second Method of Evaluation}

The exchange rate is one of the instruments of adjustment of monetary policy. 
One of the major challenges facing most of the empirical work of our days is the determination of the degree of misalignments of the exchange rate. In fact, the difficulty lies in the determination of the equilibrium level of the real exchange rate.

The objective of this second section is to describe the periods of overvaluation and under evaluation in order to detect the magnitude of current misalignments and to determine the exchange rate behavioral.

Our second method of assessment is based on equilibrium exchange rate behavioral method. This last has been initiated by ([16] [17] [18]). This method has the advantage of making account of the evolution of a theoretical model of exchange rates in order to measure the equilibrium exchange rate and identify potential misalignments of the exchange rate.

According to the approach of the exchange rate advanced behavioral by Mac Donald under the assumption of rational expectations, the current exchange rate is as follows:

$$
\text { TxChCourant }_{t}=\text { TxChSystematique }{ }_{t}+\Delta i_{t}
$$

In order to estimate the equilibrium exchange rate behavioral, we need to identify the main determinants of the exchange rate. These will be used as the variables to introduce in a model VECM.

\subsection{Definition of Variables to Retain}

In this work, we retain the following variables:

\subsubsection{The Differential of Real Interest Rates ( $\Delta i)$}

This gap in real interest rate $\left(i-i^{*}\right)$ has a positive effect on the exchange rate in accordance with the theory of the parity of the rate of interest not covered advanced by [19]. This parity establishes that the difference between the anticipation of the exchange rate and the spot exchange rate is related to the difference between the rate of interest is domestic and the rate of interest abroad:

$$
\frac{E_{t}\left(S_{t+1}\right)-S_{t}}{S_{t}}=\frac{i-i^{*}}{1+i^{*}}
$$

where $E_{t}\left(S_{t+1}\right)$ is the anticipation on the spot future exchange rate, or exchange rate ex-ante, formed on the basis of the information available at $\mathrm{t}$ a given moment $t^{1}$

In order to ensure a positive differential interest rate, the previous equation become:

$$
\frac{E_{t}\left(S_{t+1}\right)-S_{t}}{S_{t}}=\frac{\left|i-i^{*}\right|}{1+i^{*}}
$$

The domestic real interest rate is defined as the difference between the nominal interest rate and the rate of inflation of each country of our sample. Oth-

${ }^{1}$ This condition will be verified if investors consider foreign bonds and national level such as perfect substitutes and if there is not an obstacle to the international movement of capital. 
erwise, the foreign real rate of interest abroad is defined as the difference between the nominal interest rate and the rate of inflation in the euro area since the trading partners of each country of study are already part of the euro area.

\subsubsection{The Degree of Openness of Each Economy (DO)}

The usefulness of integrating this rate in the analysis comes from the developed countries to [20]. Among the latter, the devaluation of the real exchange rate is mainly due to the increase in the degree of openness of the economy.

Thus, the rate of openness enables us to calculate the level of the external constraint. It may play a role in amplifying the impact of shocks to real exchange rates.

The rate of openness is calculated as follows:

$$
\frac{X+M}{2 P I B} \times 100
$$

\subsubsection{The Rate of Coverage (TC)}

The rate of coverage is an indicator that measures the economic independence of each country. Recently, [21] have integrated this rate in their model to determine the misalignments of the exchange rate and to study the persistence of inflation for the countries of Latin America.

In effect, the rate of coverage is calculated as follows:

$$
\frac{X}{M} \times 100
$$

This rate is calculated for all the countries of our sample with the exception of Portugal which denotes a null value of imports throughout the duration of the analysis.

\subsubsection{The Productivity (PROD)}

The productivity variable allows you to capture the Balassa-Samuelson effect of the countries of our study, that is to say the trend in the relative price of tradable goods in relation to the non-tradable.

[2] prove that there is a positive correlation between the variable PROD and the real exchange rate.

Generally, productivity is measured by the ratio of GDP per capita in each country of our study on the GDP per capita of the euro zone since we assume in this analysis that the trading partners of each country of study are already part of the euro area.

The variable PROD is calculated as follows:

$$
\text { PROD }=\frac{\log \left(I P_{i}\right)}{\log \left(I P_{\text {zeuro }}\right)}
$$

where $\log ($.$) is the logarithm function. I P_{i}$ et $I P_{\text {zeuro }}$ represent respectively the index of production for each of the countries of our study and the production index of the euro area.

The variables mentioned above are linked as follows: 


$$
\operatorname{TxChaComp}_{t}=\alpha \Delta i_{t}+\beta D O_{t}+\gamma T C_{t}+\phi P R O D_{t}+u_{t}
$$

The result is a good illustration of our model VECM from the following vec-

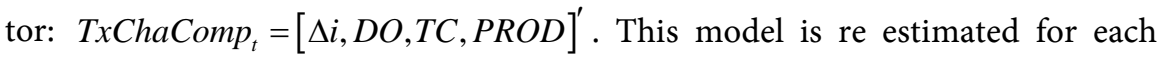
country of our sample.

The data used are monthly and cover the period from $2007 \mathrm{~m} 7$ to $2012 \mathrm{~m} 8$.

A number of pre-testing are associated with the estimation of the VECM. The unit root tests of $\mathrm{ADF}$ and Phillips-Perron prove that the series are integrated of order 1 . The test for cointegration proves the existence of three long-term relationship between the exchange rate and the variables selected. The results relating to the first method are explored in Appendix B.

\subsection{Interpretation of Results Relating to the Appendix B}

\subsubsection{The Case of the Countries of the Zone Med: Tunisia and Egypt}

The graph of the misalignments explored in Figure 11 for the case of the Tunisia shows that the Tunisian dinars is globally under assessed on the whole of the period. In effect, there is very little period of overvaluation especially during the month of August 2007, the month of September 2008 and the month of June 2009. By contrast, we note several date of depreciation of the national currency in October 2007, April 2008, November 2008, January 2009, April 2009, October 2009, January 2010, March 2010, July 2010 and March 2011.

The evolution of the exchange rate translates this fact by important misalignments especially in term of gap at the level of balance.

Figures in blue presented in the Appendix B denote well an attempt of rectification of floating exchange rate by the equilibrium exchange rate behavioral. Figure 12 shows a difficulty of rectification of this equilibrium for the case of Egypt.

In the long term, the progressive liberalization of capital movements will require greater flexibility of the exchange rate in the case of Tunisia and Egypt. This movement must be gradual and be accompanied by the strengthening of the institutions of economic policies.

The graph of the misalignments for the case of Egypt proves that the Egyptian pound is broadly overstated on the whole of the period. In effect, there is very little period of under-evaluation, notably during the month of October 2008, the month of April 2010 and October of the year 2010 and 2011. By contrast, we note several date of appreciation of the Egyptian pound in April 2008, February 2010, September 2010 and February 2011.

The evolution of the exchange rate translates this fact by important misalignments especially in term of gap at the level of balance.

\subsubsection{The Case of the Countries of the Euro Area: Greece, Portugal, Spain and Italy}

The graph of the misalignments for the case of the four countries of study of the euro area is identical in appearance with a clear difference in October 2008, in May 2011 and in June of the same year for Italy, Spain, Greece and Portugal (see 
Figures 13-16 explored in Appendix B). However the magnitude of the overvaluation and the under evaluation differs from one country to another. The under-evaluation is shrinking differently and is unable to join the situation of balance in the same way. The evolution of the exchange rate translates this fact by important misalignments especially in term of gap at the level of balance.

\section{The Third Method of Evaluation}

The VAR model, proposed by [1], became a technique commonly used in the econometric analysis and is adaptable to many approach in economy ([3]). In this study, we will use a model of autoregressive vector to settings variables in the time and stochastic volatility TVP-VAR. This recent technique in the analysis of macroeconomic issues allows us to enter the variable nature in the time of the underlying structure of the economy in a flexible and robust ([22]). The parameters of the VAR specification are supposed to follow a process of random walk of the first order, thus incorporating the temporary changes and settings permanent. The inclusion of stochastic volatility is an important aspect in this model TVP-VAR. In many situations, a data-generation process of economic variables seems to have the drift of the coefficients and shocks of stochastic volatility. In this case, the application of a model with parameters that vary in time, but with a constant volatility may lead to biased estimates of the coefficients, because a possible variation of the volatility of disturbances or wrong specification is ignored. The model TVP-VAR to stochastic volatility allows you to avoid this specification error. Although the stochastic volatility makes this difficult to estimate due to the intransigence of the likelihood function, the model can be estimated using Markov chain Monte Carlo (MCMC) in the framework of a Bayesian inference.

We inspire during this research work of advanced of [22]. The latter considers a VAR model to variable parameter in the time and stochastic volatility of the form:

$$
y_{t}=c_{t}+B_{1 t} y_{t-1}+\cdots+B_{s t} y_{t-S}+A_{t}^{-1} \Sigma_{t} \varepsilon_{t}
$$

For $t=s+1, \cdots, T$, where $y_{t}$ is a vector of the observed variables of dimension $(k \times 1), B_{1 t}, \cdots, B_{s t}$ are matrices of coefficients ranging in the time of dimension $(k \times k)$, et $A_{t}, \Sigma_{t}$ are parameters varying in time.

We will define $a_{t}$ as the vector stacked triangular elements of $A_{t}$; et $h_{t}=\left(h_{1 t}, \cdots, h_{k t}\right)$ where $h_{j t}=\log \left(\sigma_{j t}^{2}\right)$. The parameters varying in time are supposed to follow a random walk:

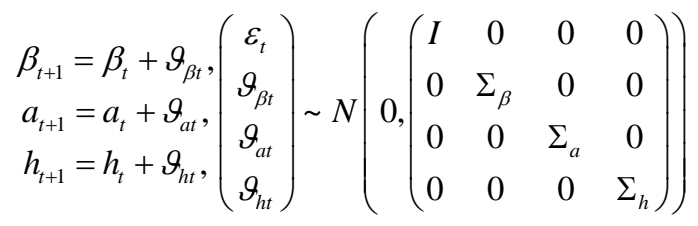

where $\Sigma_{\beta}, \Sigma_{a}$ and $\Sigma_{h}$ are matrices diagonals, $\beta_{s+1} \sim N\left(\mu_{\beta_{0}}, \Sigma_{\beta_{0}}\right)$, $a_{s+1} \sim N\left(\mu_{a_{0}}, \Sigma_{a_{0}}\right)$ and, $h_{s+1} \sim N\left(\mu_{h_{0}}, \Sigma_{h_{0}}\right)$. 
A Bayesian inference is used to estimate the models TVP-VAR by methods MCMC. The purpose of the MCMC methods is to evaluate the joint distributions a posteriori of the parameters of interest in certain densities of a priori probability that are fixed in advance.

For all of the parameters varying in time, the means and the variances are set such that: $\mu_{\beta_{0}}=\mu_{a_{0}}=\mu_{h_{0}}=0$ et $\Sigma_{\beta_{0}}=\Sigma_{a_{0}}=\Sigma_{h_{0}}=10 I$.

The results relating to this nonlinear approach are explored in Appendix C.

\subsection{Definition of Variables to Retain}

The data to remember for this third section are the interest rates, the exchange rate, the index of production and the rate of inflation. These data are monthly of $2007 \mathrm{~m} 6$ to $2012 \mathrm{~m} 8$. The data are taken from the monthly frequencies converted in millions of constant dollars and a logarithmic transformation was applied to them. These variables have been collected from the International Monetary Fund IFS. The estimate has been made by the software Oxmetrics and results related to this method are presented in Appendix C.

\subsection{Interpretation of Impulse Responses}

The results presented in Appendix C are more significant than those found in Appendix A.

\subsubsection{The Case of the Countries of the Zone Med: Tunisia and Egypt} According to Figure 17, the impact of a Tunisian shock of monetary policy is transient on the output for a duration of 12 months. Beyond this date, the response joined the situation of balance. The delay of transmission of this shock is short. However, the inflation responds in a positive way as a result of a shock of monetary policy, it does not happen to be well controlled by the monetary authorities since the transmission delay is long and lasts more than 70 months.

The Central Bank of Tunisia (BCT) has left the dinar depreciate beyond what was necessary to keep the real exchange rate stable in order to partially offset the impact of the reduction in external protection on the competitiveness.

Although the channel of the exchange rate is generally regarded as one of the powerful channels of action of monetary policy in the macroeconomic models, it does not appear to play an important role in the transmission of monetary policy. This result has been well found even with a linear model during our first section.

In the case of Egypt, and following Figure 18 which explores a shock of monetary policy, the reaction of inflation peak after a year. The shock can be regarded as transitional. While the GDP displays no significant reaction as well on the short and long term.

Nevertheless, this does not prevent us from provide a good contribution of the exchange rate channel. The latter traces the new perspective referred by the responsible to strengthen the integration of the Tunisia and Egypt in the world economy. The monetary authorities have welcomed with satisfaction the transi- 
tion phase of an exchange rate regime administered to a regime of floating exchange rate. However, after two years of the Tunisian revolution and of the Egyptian woman, the reforms will have to be accelerated to reduce the intervention of the State in the economy and energize the private sector. The depreciation is a first step in this direction and the desired flexibility of the exchange rate should enhance the resilience of these economies to external shocks and maintain their balance as well at the level internal and external.

\subsubsection{The Case of the Countries of the Euro Area: Greece, Portugal, Spain and Italy}

According to Figures 19-22 explored in Appendix C, we notice strong inequalities sometimes between the macroeconomic performance of these member countries, structural weaknesses already observable before the crisis in some countries are amplified after the crisis of the subprime and especially the sovereign debt crisis.

For Greece, the reactions of inflation and the output following a shock of monetary policy we show that the deadlines for the transmission of the monetary policy are slow. There is a problem to solve to know the budget deficit imposing the monetary authorities to adopt a few strategies of compression of public and private expenditures even if there will be of the aid on the part of the ECB. If the markets have calmed down in respect of the Spanish situation after that the ECB has announced the establishment of its safety net, the interest rate at which the investors bought the Spanish debt remains high. A large part of the expenditure of the State will be devoted to the reimbursement of the interests of the Spanish debt.

Despite the fact that the central banks have adopted a monetary policy of so-called inflation targeting, consisting to aim for the stability of the retail price, the responses of inflation following a shock of monetary policy are sometimes found positive for Italy and Greece, sometimes negative for Spain and not significant for Portugal. Our results will rub shoulders with the new advanced search of [23] which claims that the absence of inflation would of itself the stability of the financial system. Retail Price stability may well go hand in hand with strong increases in the price of assets (real estate, fellows), fed by a excessive credit expansion, itself is doped by the generous supply of liquidities at low cost by the central banks.

\section{Conclusion}

We have tried throughout this research paper to study the impact of the crisis of the subprime on a few economies of the Euro-Med zone. To do this, we have advanced three methods to examine the channels of transmission of the effects of monetary policy through the channel of the exchange rate. The first method is to estimate a linear model structural. The second method is based on the calculation of the determinants of the exchange rate and the determination of the exchange rate behavioral. The third nonlinear method allows us to evaluate the 
channel of the exchange rate in a context of financial instability. For the exchange policy, the devaluation may not always be a solution to a real problem of competitiveness linked to the offer exportable national property. Currently, the channel of the exchange rate is not important in the countries of the Euro-Med zone since the improvement of the external competitiveness of local products requires a good control of inflation, an appropriate exchange rate policy and a good remedy to the debt crisis.

\section{References}

[1] Sims, C.A. (1980) Macroeconomics and Reality. Econometrica, 48, 1-48. https://doi.org/10.2307/1912017

[2] Berau, S., Mignon, V. and Lopez-Villavicencio, A. (2010) Nonlinear Adjustment of the Real Exchange Rate towards Its Equilibrium Value: A Panel Smooth Transition Error Correction Modelling. Economic Modelling, 27, 404-416. https://doi.org/10.1016/j.econmod.2009.10.007

[3] Hachicha, A. and Lee, C.F. (2009) Are Structural VARs with Long-Run Restrictions Useful for Developing Monetary Policy Strategy in Egypt? Review of Pacific Basin Financial Markets and Policies, 12, 509-527. https://doi.org/10.1142/S0219091509001721

[4] Bates, S. and Hachicha, A. (2009) Empirical Analysis of Monetary Transmission in Tunisia: What do SVAR Models Tell Us? The Open Economics Journal, 2, 1-9. https://doi.org/10.2174/1874919400902010001

[5] Rotemberg, J. and Woodford, M. (1992) Oligopolistic Pricing and the Effects of Aggregate Demand on Economic Activity. The Journal of Political Economy, 100, 1153-1207. https://doi.org/10.1086/261857

[6] Fry, R. and Pagan, A. (2011) Sign Restrictions in Structural Vector Auto- Regressions: A Critical Review. Journal of Economic Literature, American Economic Association, 49, 938-960. https://doi.org/10.1257/jel.49.4.938

[7] Sims, C.A., Stock, J.H. and Watson, M.W. (1990) Inference in Linear Time Series Models with Some Unit Roots. Econometrica, 58, 113-144.

https://doi.org/10.2307/2938337

[8] Coudert, V. And Mojon, B. (1997) Asymétries financières et transmission de la politique monétaire en Europe. [Financial Asymmetries and Transmission of the Monetary Policy in Europe.] Economie et Prévision, 128, 41-60.

https://doi.org/10.3406/ecop.1997.5848

[9] Creel, J. and Levasseur, S. (2006) Canaux de transmission de la politique monétaire dans l'UE. Le cas de trois nouveaux entrants. [Channels of Transmission of Monetary Policy in the EU. The Case of Three New Entrants.] Revue économique, 57, 881-898. https://doi.org/10.3917/reco.574.0881

[10] Hachicha, A. and Chaabane, A. (2013) Identification des canaux de transmission de la politique monétaire en Tunisie. [Identification of the Channels Monetary Policy Transmission in Tunisia.] Revue Tunisienne d'Economie et de Gestion, No. 31.

[11] Hachicha, A. and Chaabane, A. (2007) Monetary Policy Transmission Mechanism in Tunisia. Euro-Mediterranean Economics and Finance Review, 6, 104-126.

[12] Mishkin, F. (2015) Central Bank of Chile: Central Banking after the Crisis. In: Bauducco, S., Christiano, L. and Raddatz, C., Eds., Macroeconomic and Financial Stability: Challenges for Monetary Policy Sixteenth 16th Annual Conference of the 
Central Bank of Chile, Central Bank of Chile, Santiago, 23-59.

[13] Mishkin, F. (1996) The Channels of Monetary Transmission: Lessons for Monetary Policy. NBER Working Paper Series 5464. https://doi.org/10.3386/w5464

[14] De Haan, J. and Klomp, J.K. (2011) Banking Risk and Regulation: Does One Size Fit All? DNB Working Papers 323, Netherlands Central Bank, Research Department.

[15] Mishkin, F. (2011) Monetary Policy Strategy: Lessons from the Crisis. NBER Working Paper Series Working Paper n 16755. https://doi.org/10.3386/w16755

[16] Clark, P.B. and Mac Donald, R. (2003) Filtering the BEER: A Permanent and Transitory Decomposition. Global Finance Journal, 15, 29-56.

[17] Kim, H. and Mac Donald, R. (2010) Equilibrium Exchange Rate Determination and Multiple Structural Changes. Working Papers 2010-14, Business School Economics, University of Glasgow.

[18] Mac Donald, R. and Dias, P. (2007) Behavioural Equilibrium Exchange Rate Estimates and Implied Exchange Rate Adjustments for Ten Countries. University of Glasgow and Peterson Institute of International Economics.

[19] Cumby, R. and Obstfeld, E.M. (1981) A Note on Exchange-Rate Expectations and Nominal Interest Differentials: A Test of the Fisher Hypothesis. Journal of Finance, American Finance Association, 36, 697-703.

[20] Goldfajn, I. and Valdés, R. (1999) The Aftermath of Appreciations. Quarterly Journal of Economics, 114, 229-262. https://doi.org/10.1162/003355399555990

[21] Giannellis, N. and Koukouritakis, M. (2013) Exchange Rate Misalignment and Inflation Rate Persistence: Evidence from Latin American Countries. International Review of Economics and Finance, 25, 202-218.

https://doi.org/10.1016/j.iref.2012.07.013

[22] Nakajima, J. (2011) Time-Varying Parameter VAR Model with Stochastic Volatility: An Overview of Methodology and Empirical Applications. Monetary and Economic Studies, 29.

[23] Perrut, D. (2012) La régulation financière après la crises des "subprimes" quelles leçons et quelles réformes? [Financial Regulation after the "Subprime" Crisis, What Lessons and What Reforms?] Foundation Robert Schuman, Policy Paper, Juillet. 


\section{Appendix A: Relating to the Results of the First Method}

Med Zone
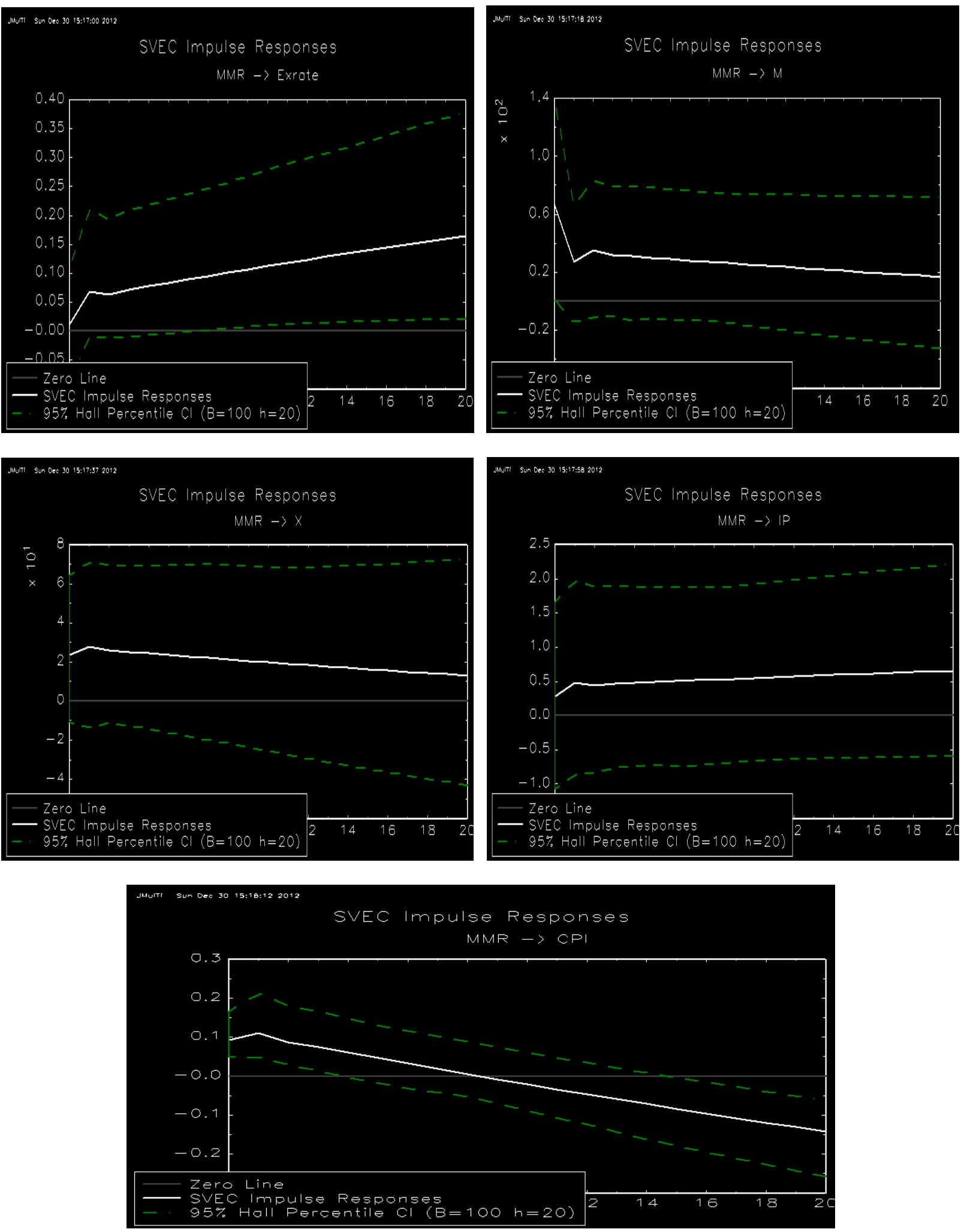

Figure 1. Functions of impulse responses following a shock of monetary policy (case of the Tunisia). 

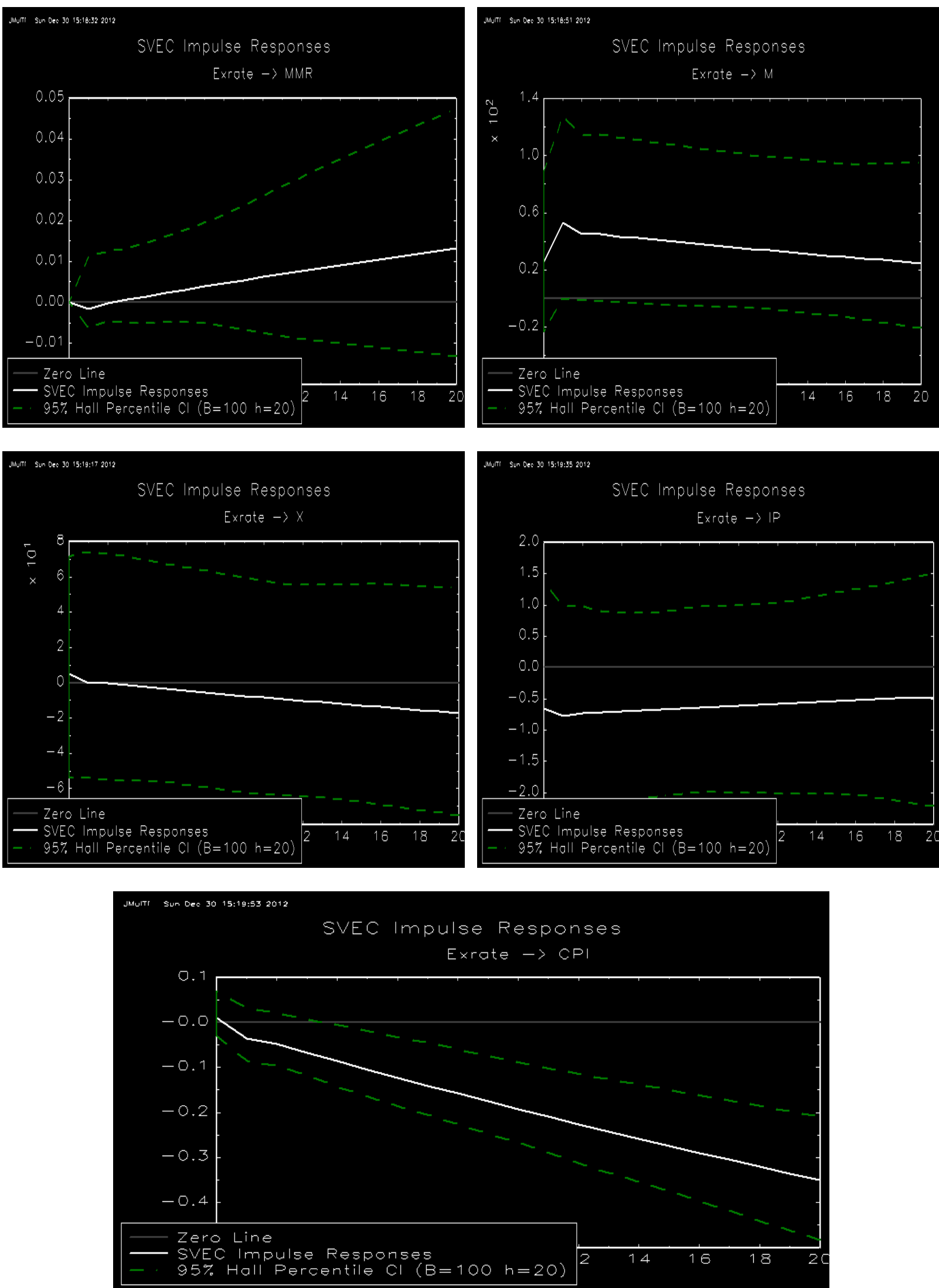

Figure 2. Functions of impulse responses following an impact of the exchange rate (in the case of Tunisia). 

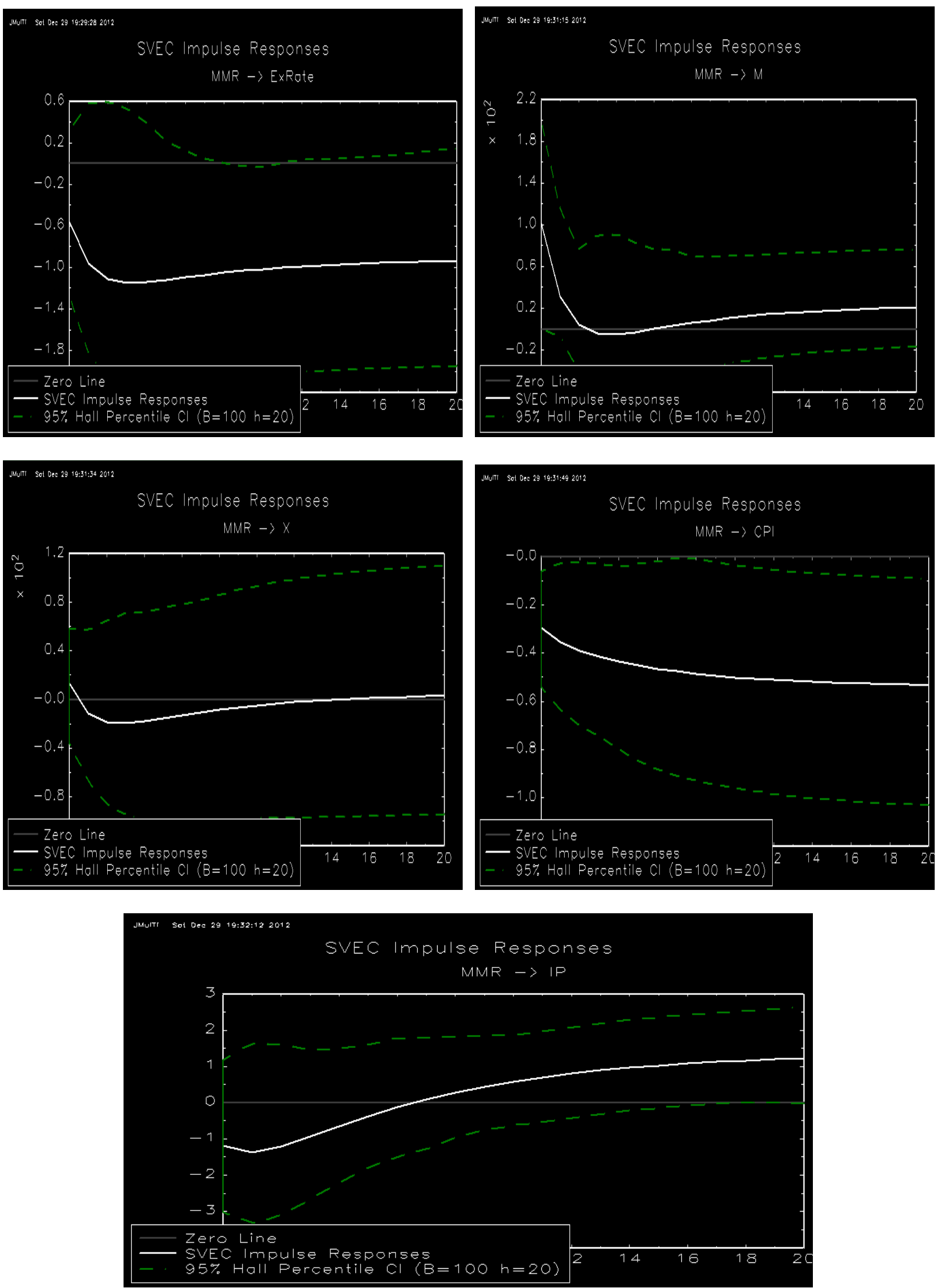

Figure 3. Functions of impulse responses following a shock of monetary policy (case of the Egypt). 

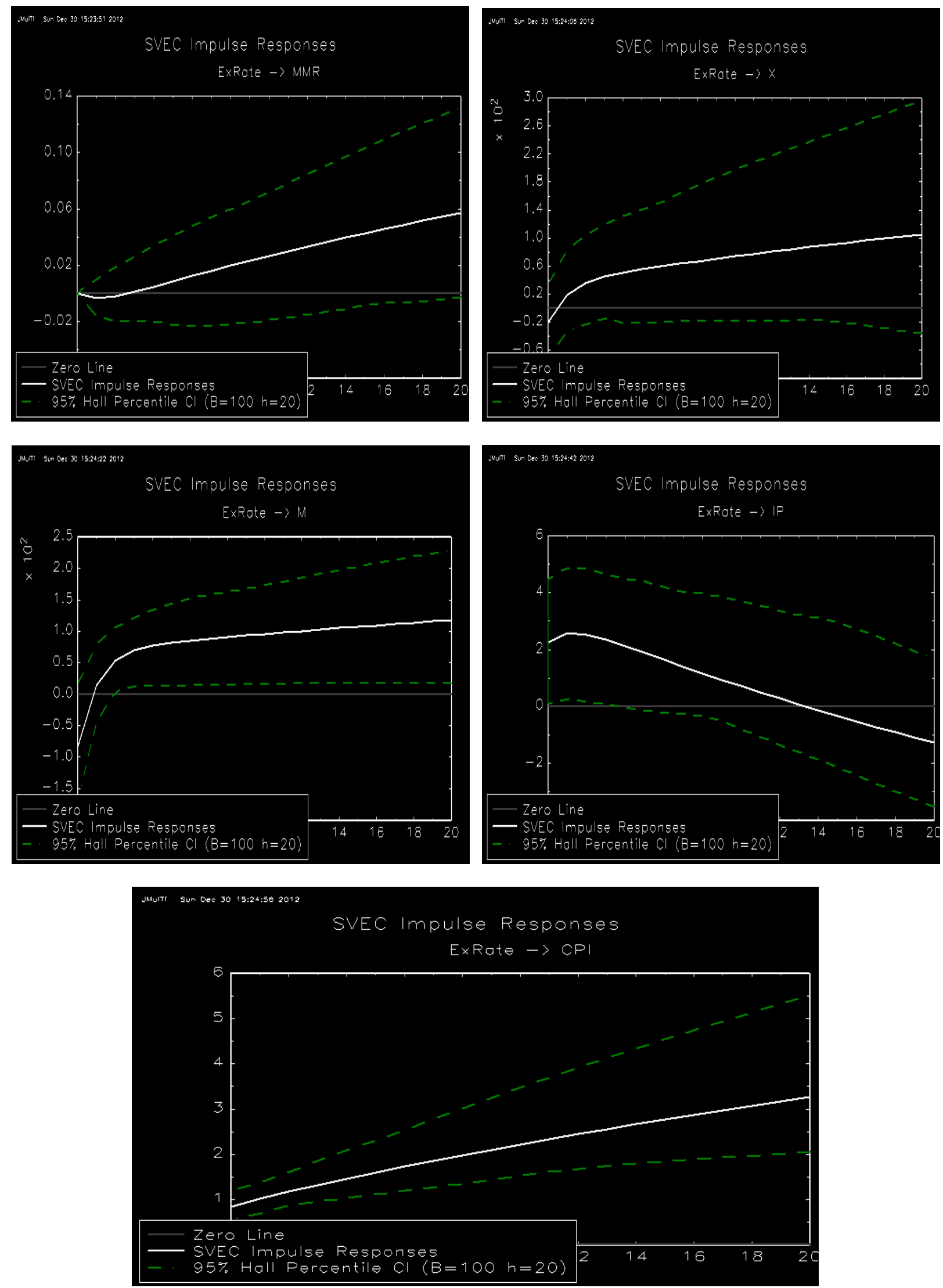

Figure 4. Functions of impulse responses following an exchange rate shock (case of the Egypt). 


\section{Euro Zone}
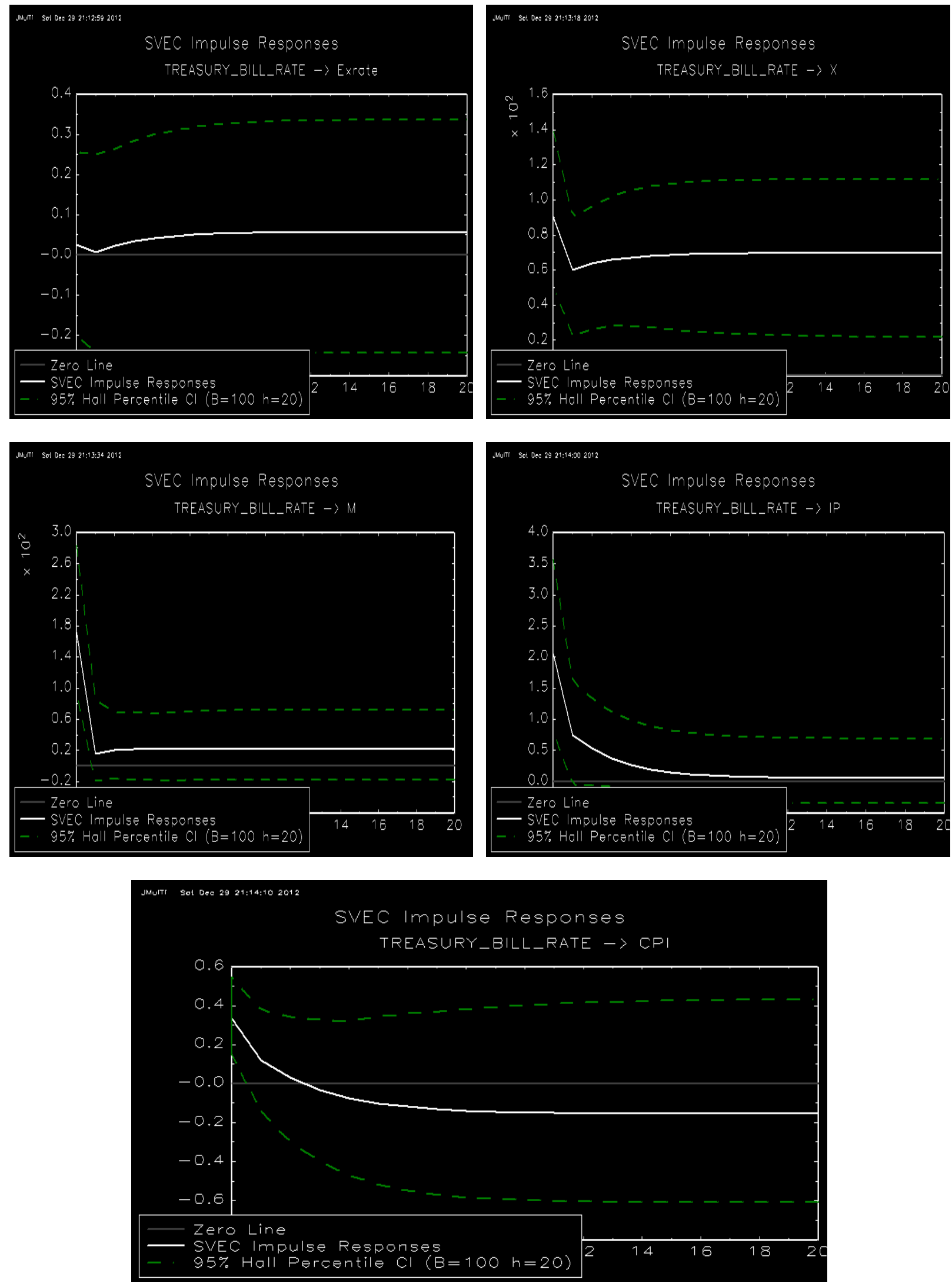

Figure 5. Functions of impulse responses following a shock of monetary policy (case of Greece). 

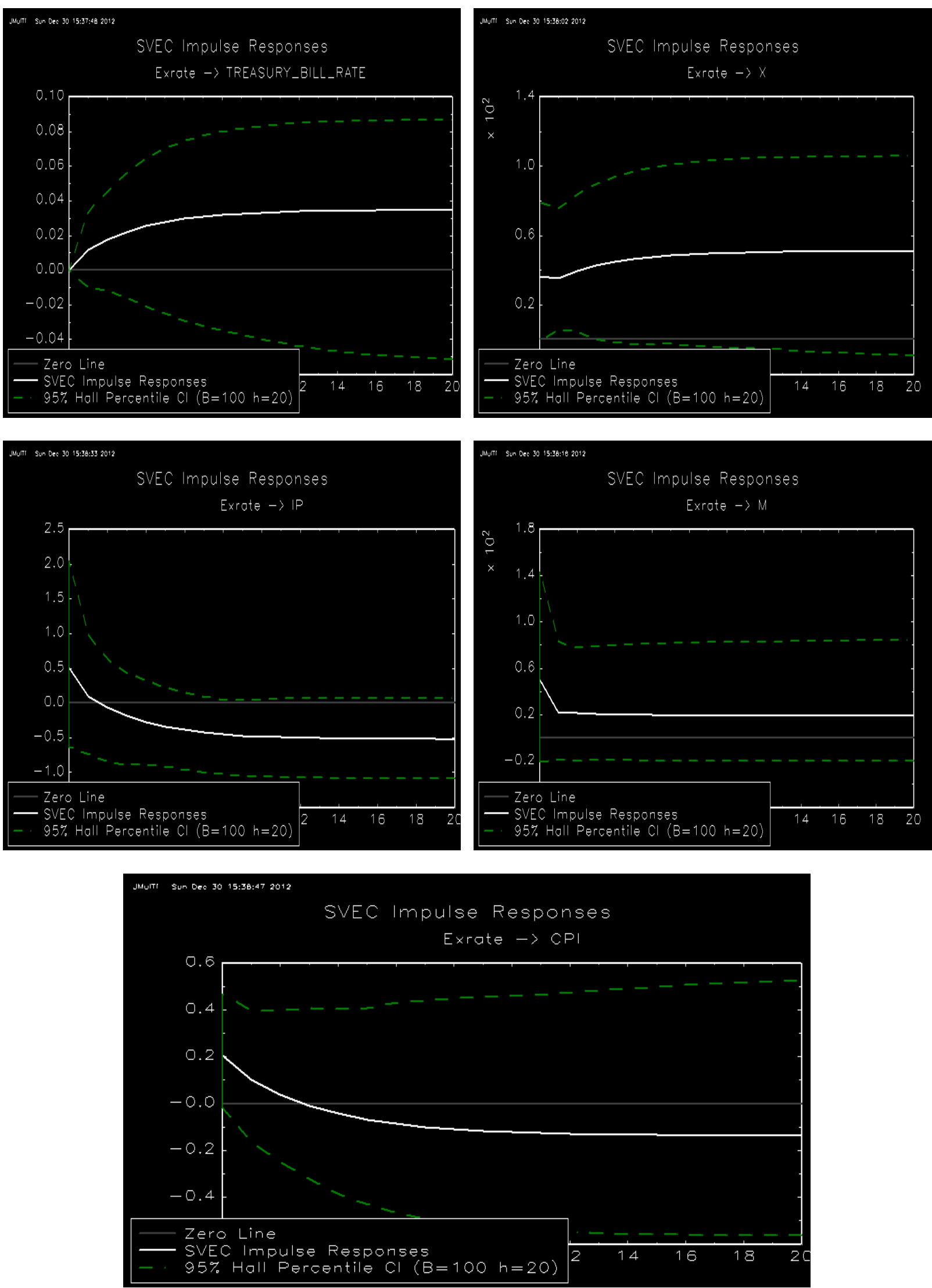

Figure 6. Functions of impulse responses following a shock of monetary policy (case of Greece). 

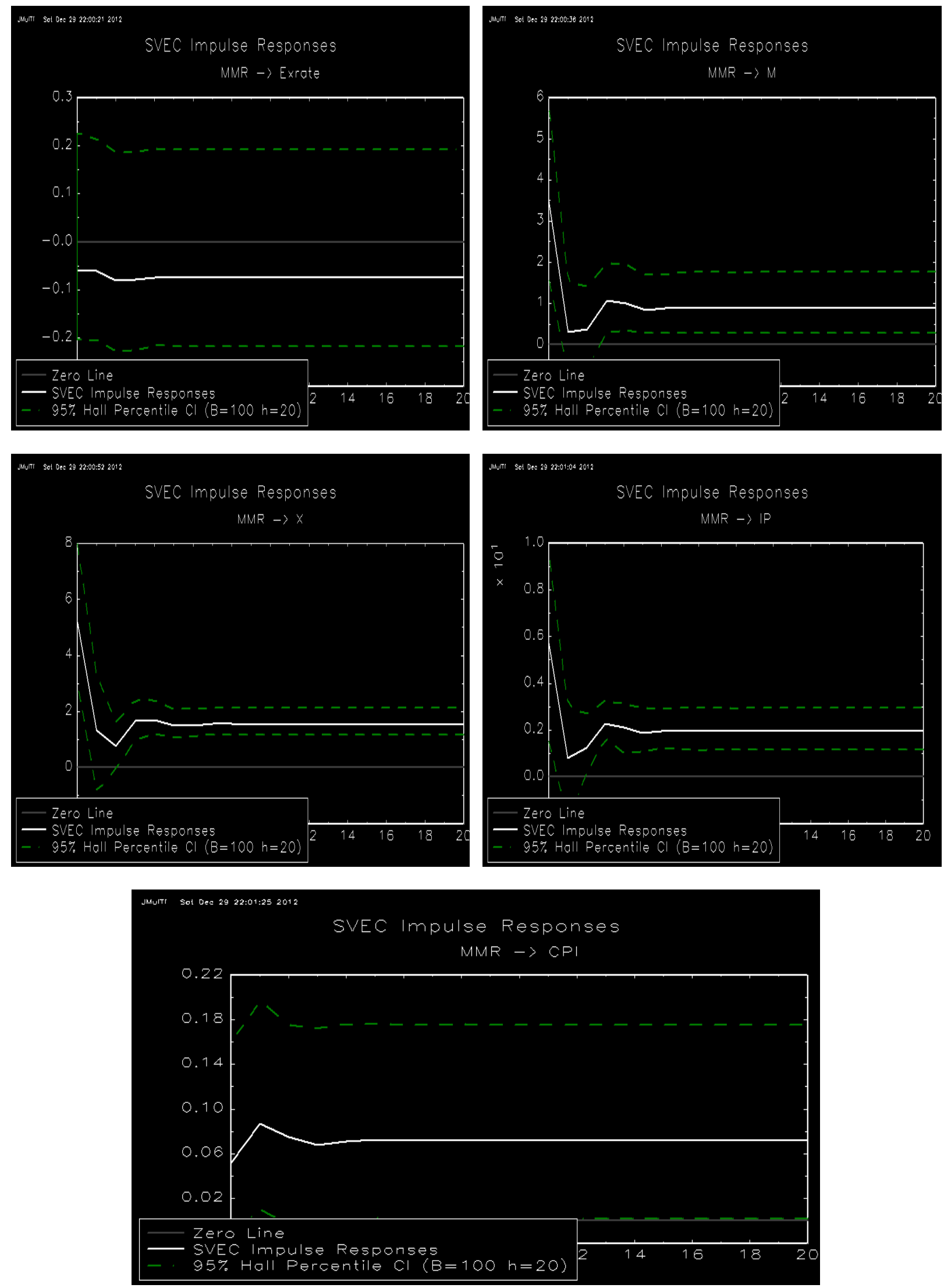

Figure 7. Functions of impulse responses following a shock of monetary policy (case of Italy). 

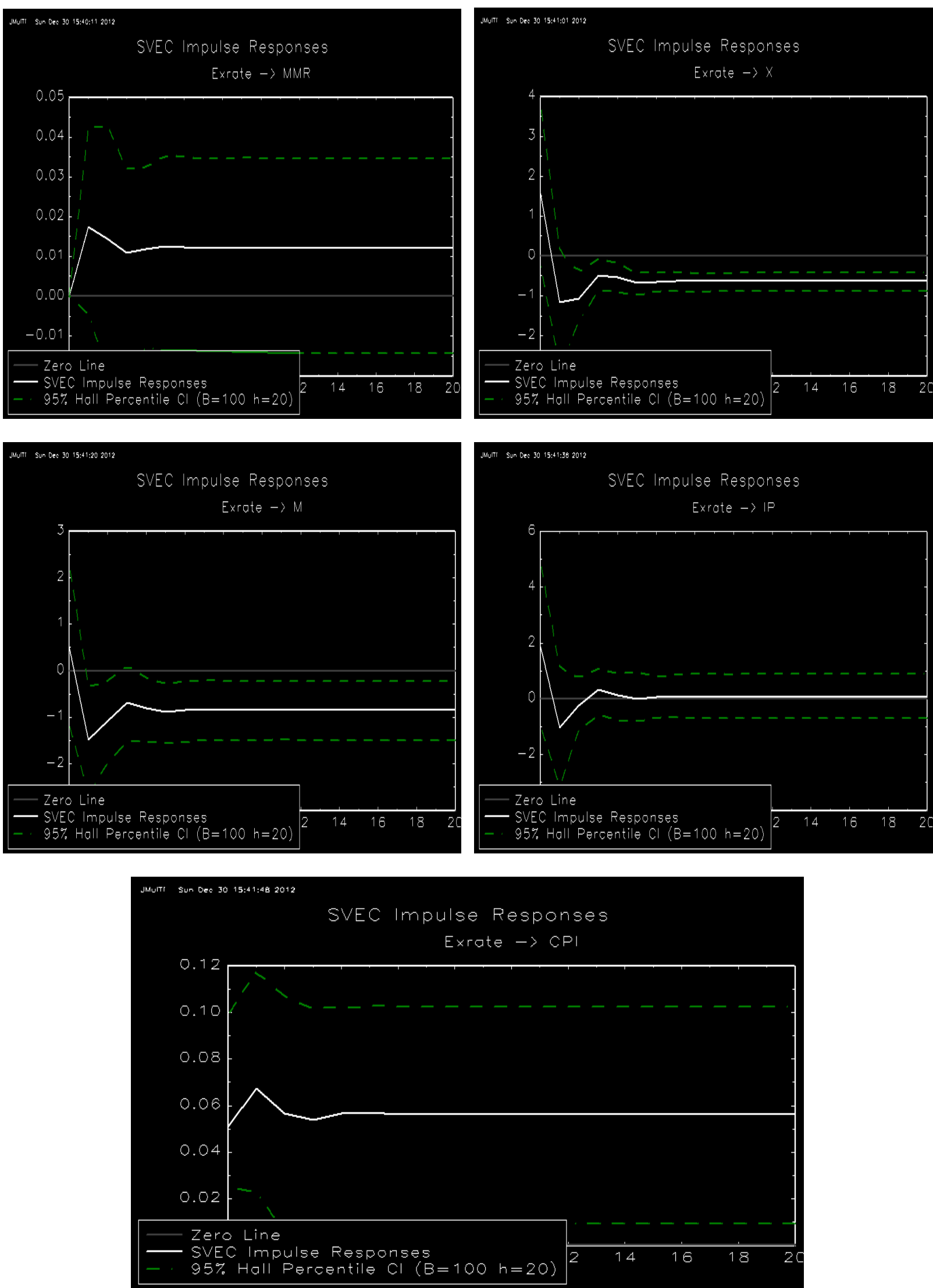

Figure 8. Functions of impulse responses following an exchange rate shock (case of Italy). 

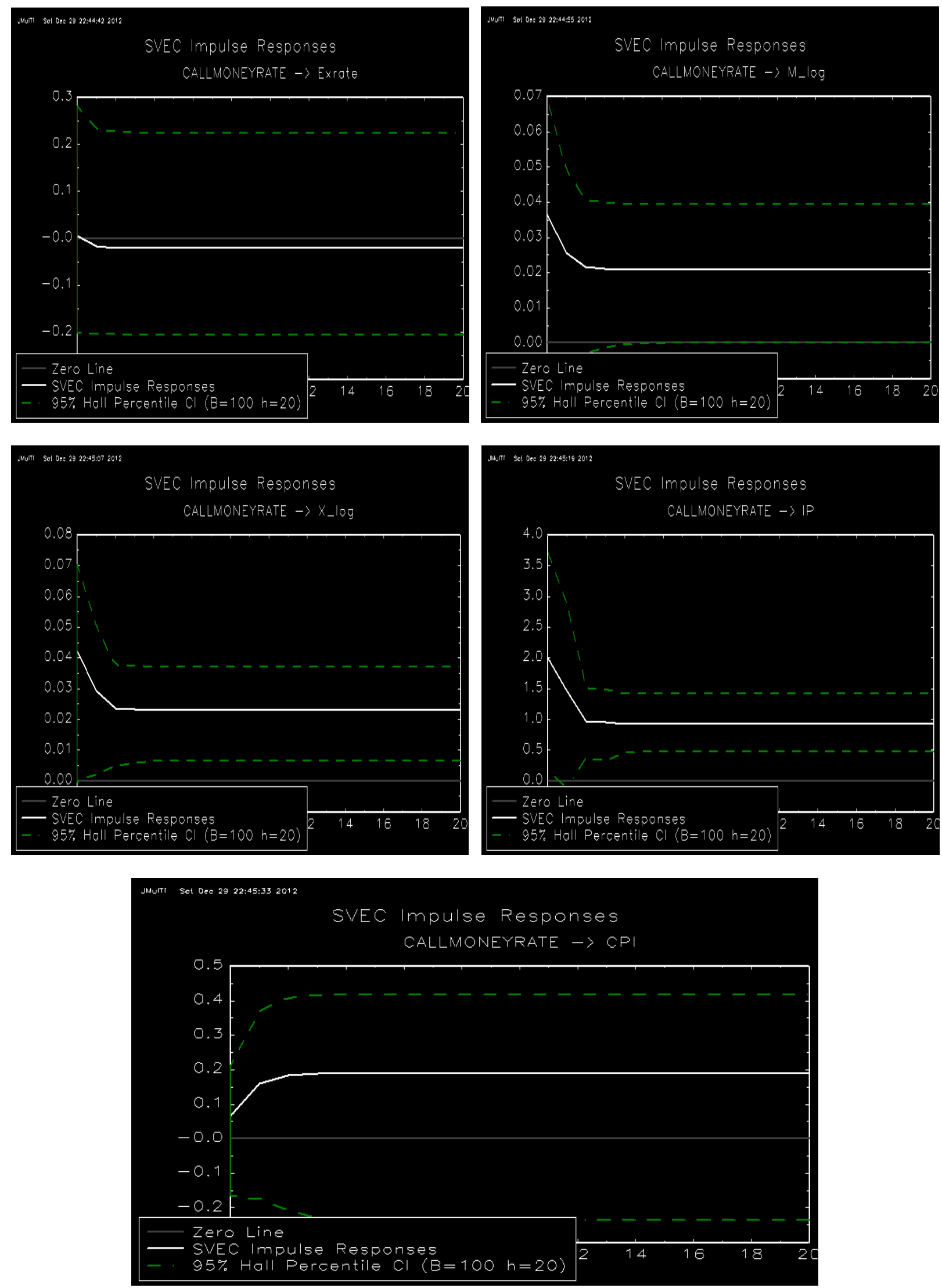

Figure 9. Functions of impulse responses following a shock of monetary policy (case of Spain). 

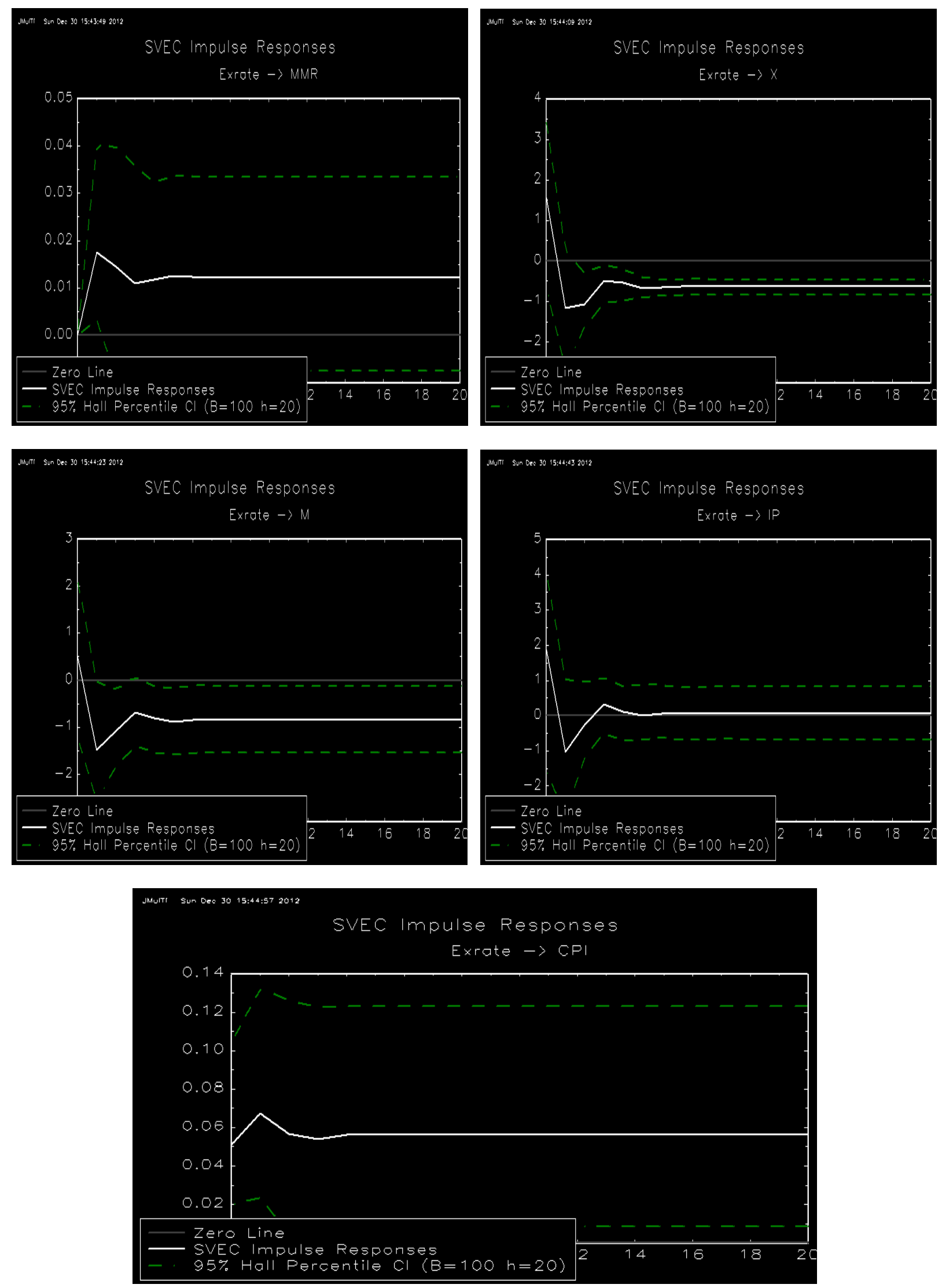

Figure 10. Functions of impulse responses following an exchange rate shock (case of Spain). 


\section{Appendix B: Relating to the Results of the Second Method}
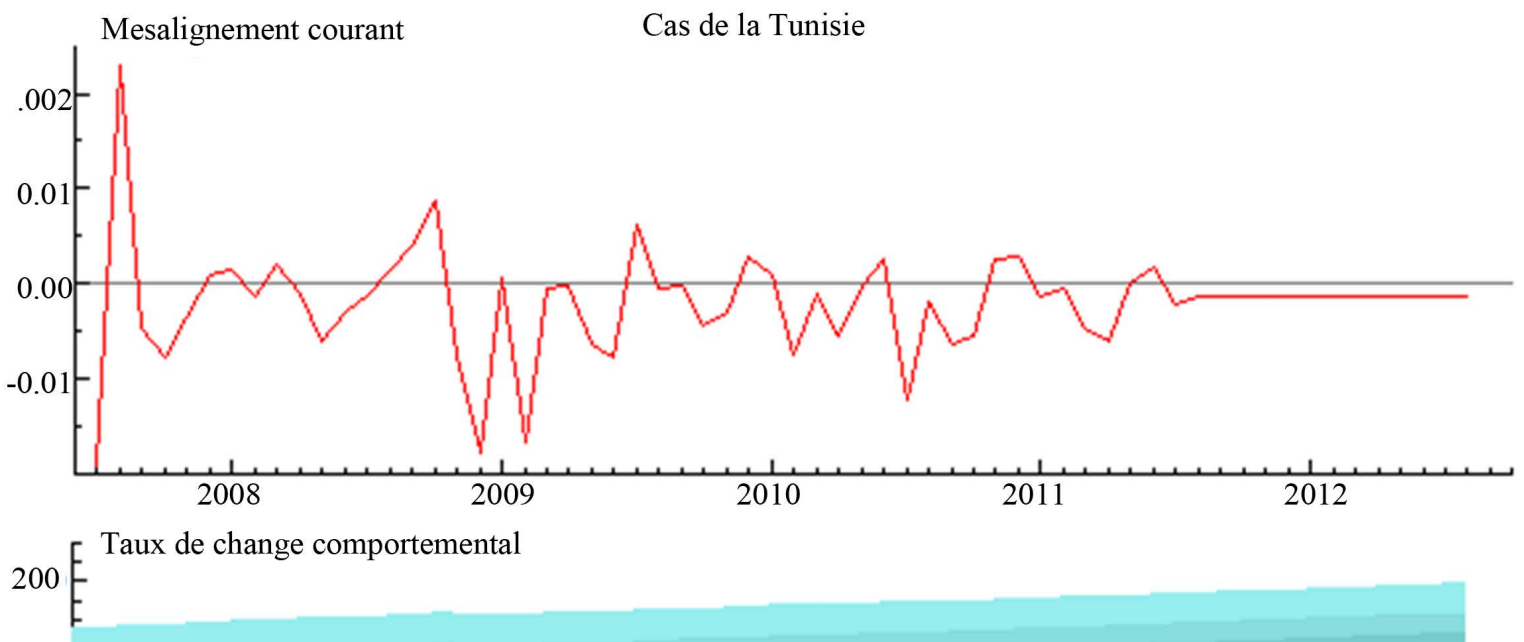

100

0

$-10$

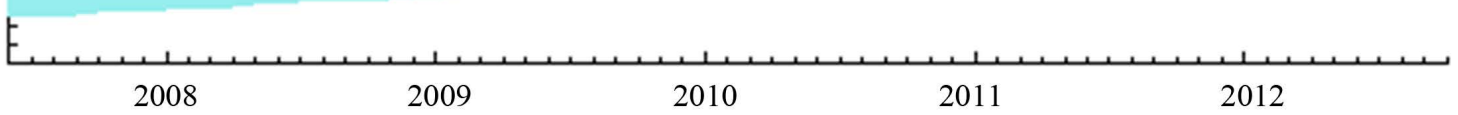

Figure 11. The case of Tunisia.
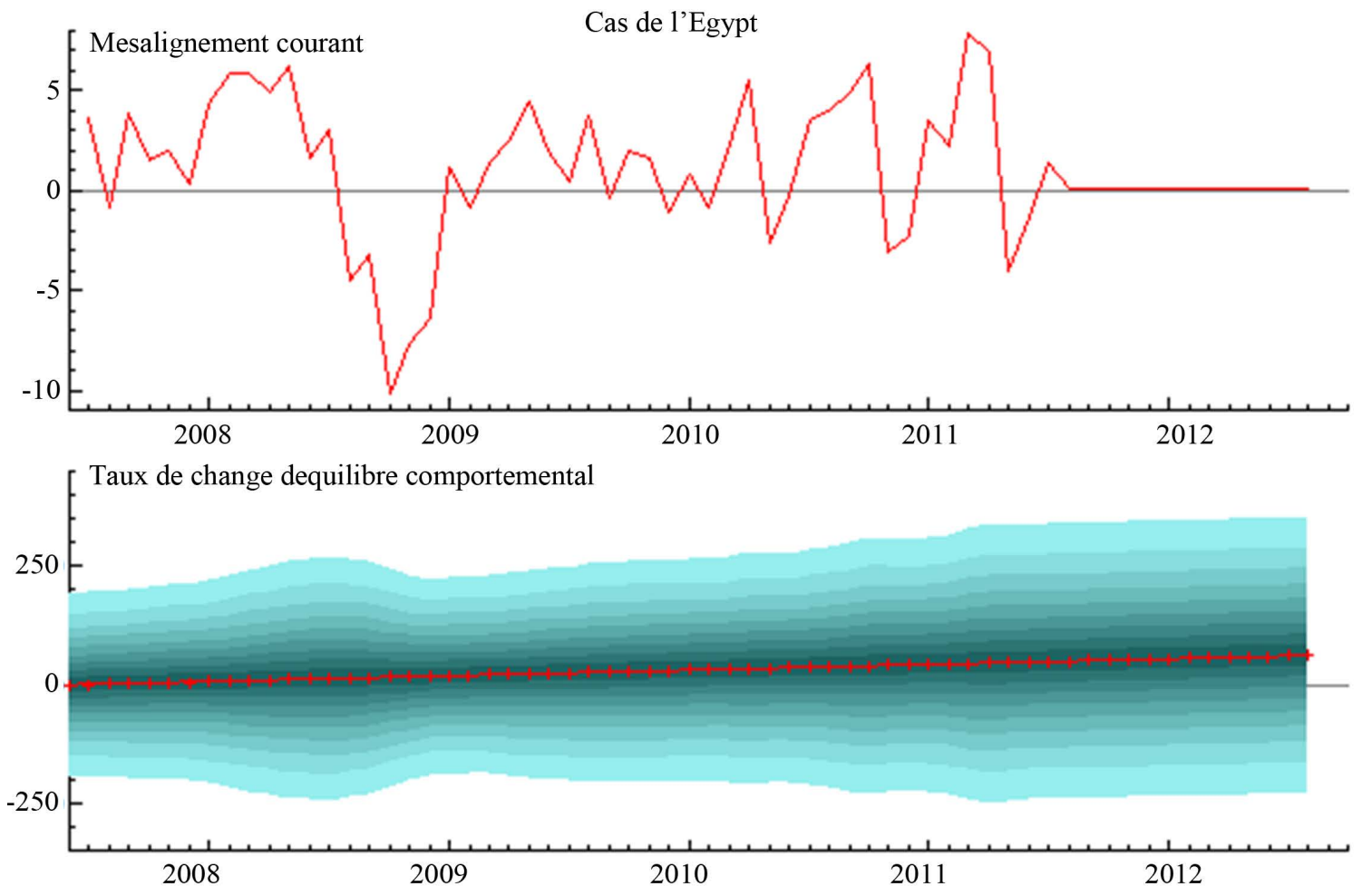

Figure 12. The case of Egypt. 
Cas de la Grece
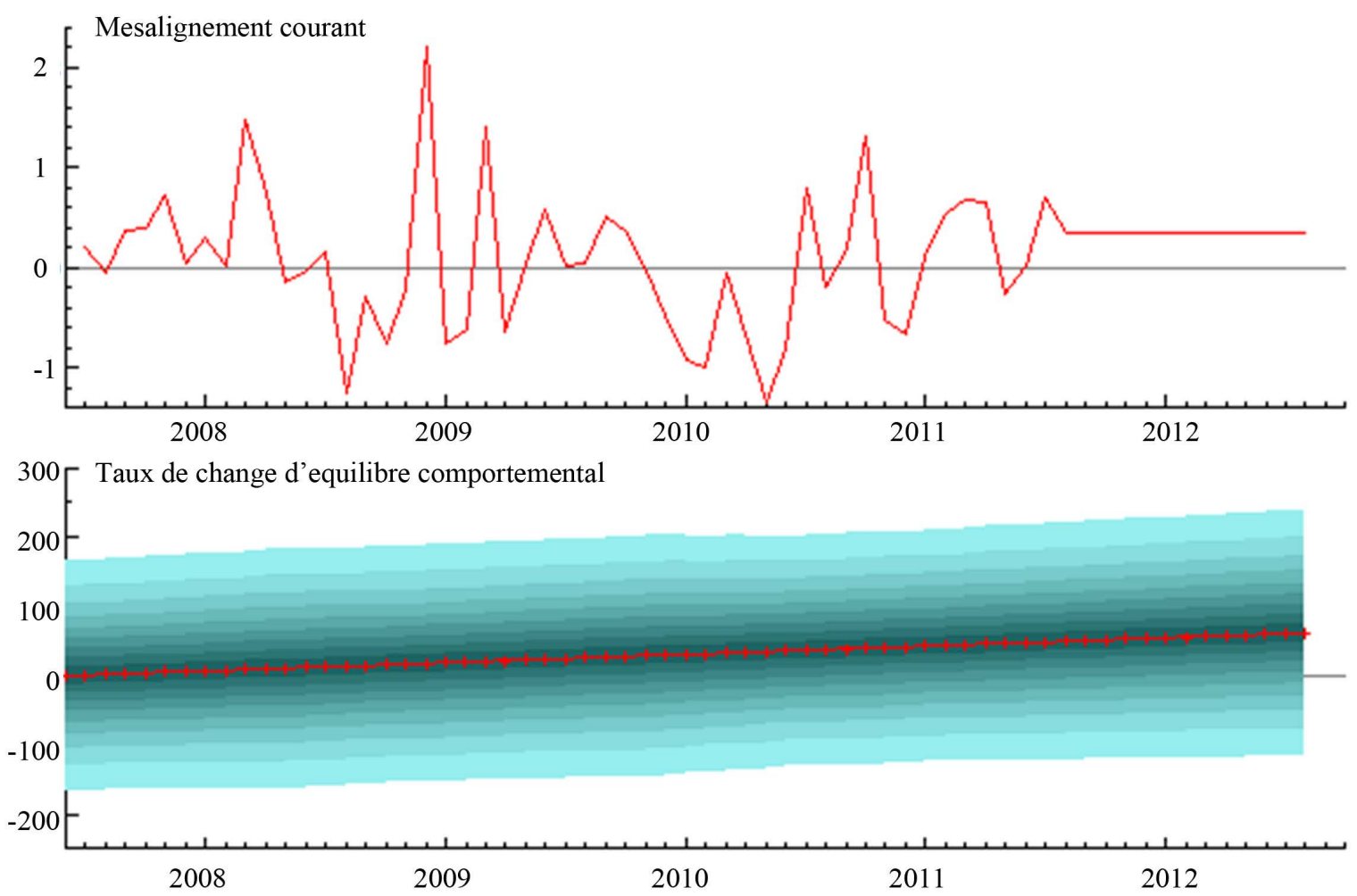

Figure 13. The case of Greece.
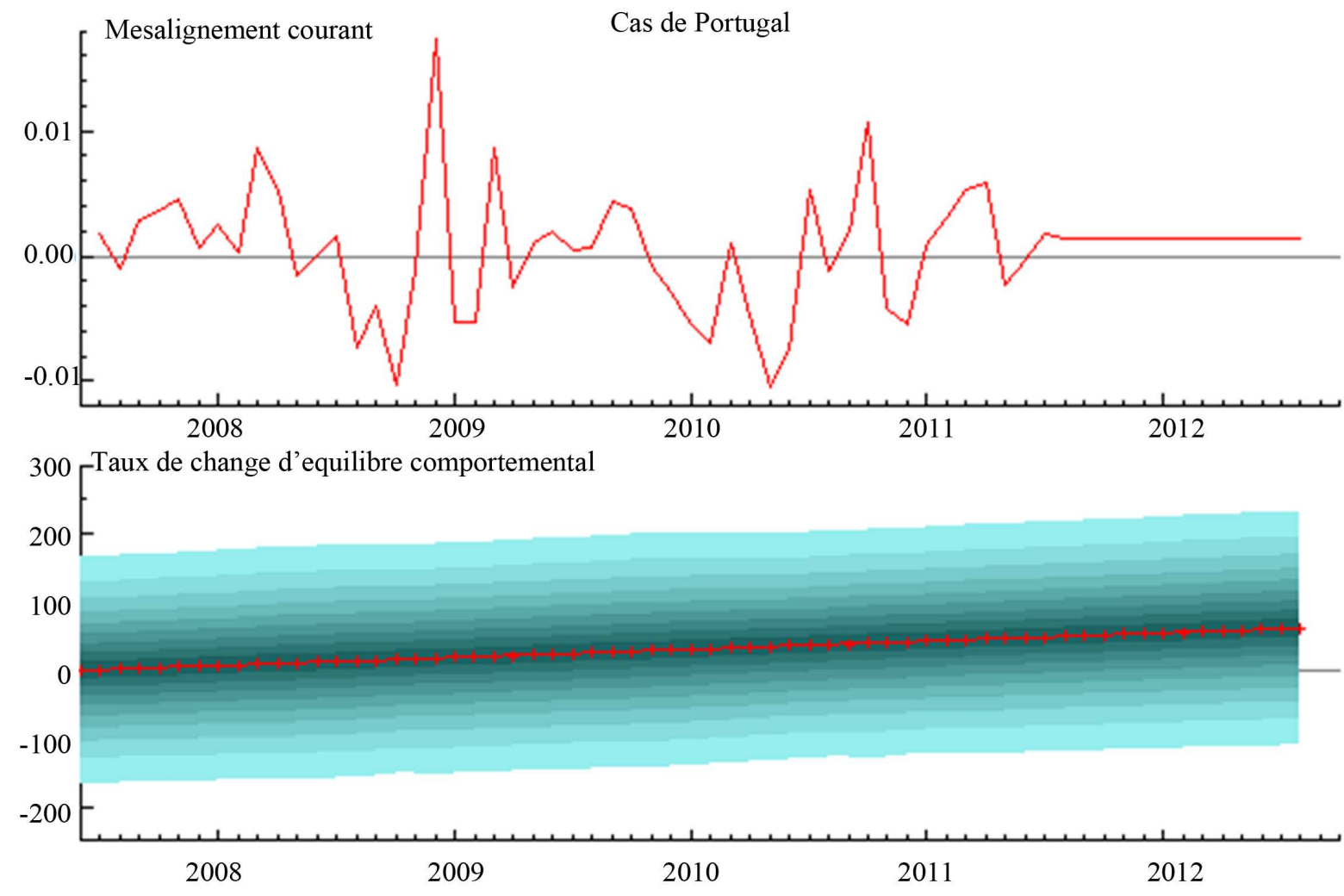

Figure 14. The case of Portugal. 


\section{Cas de 1'Espagne}
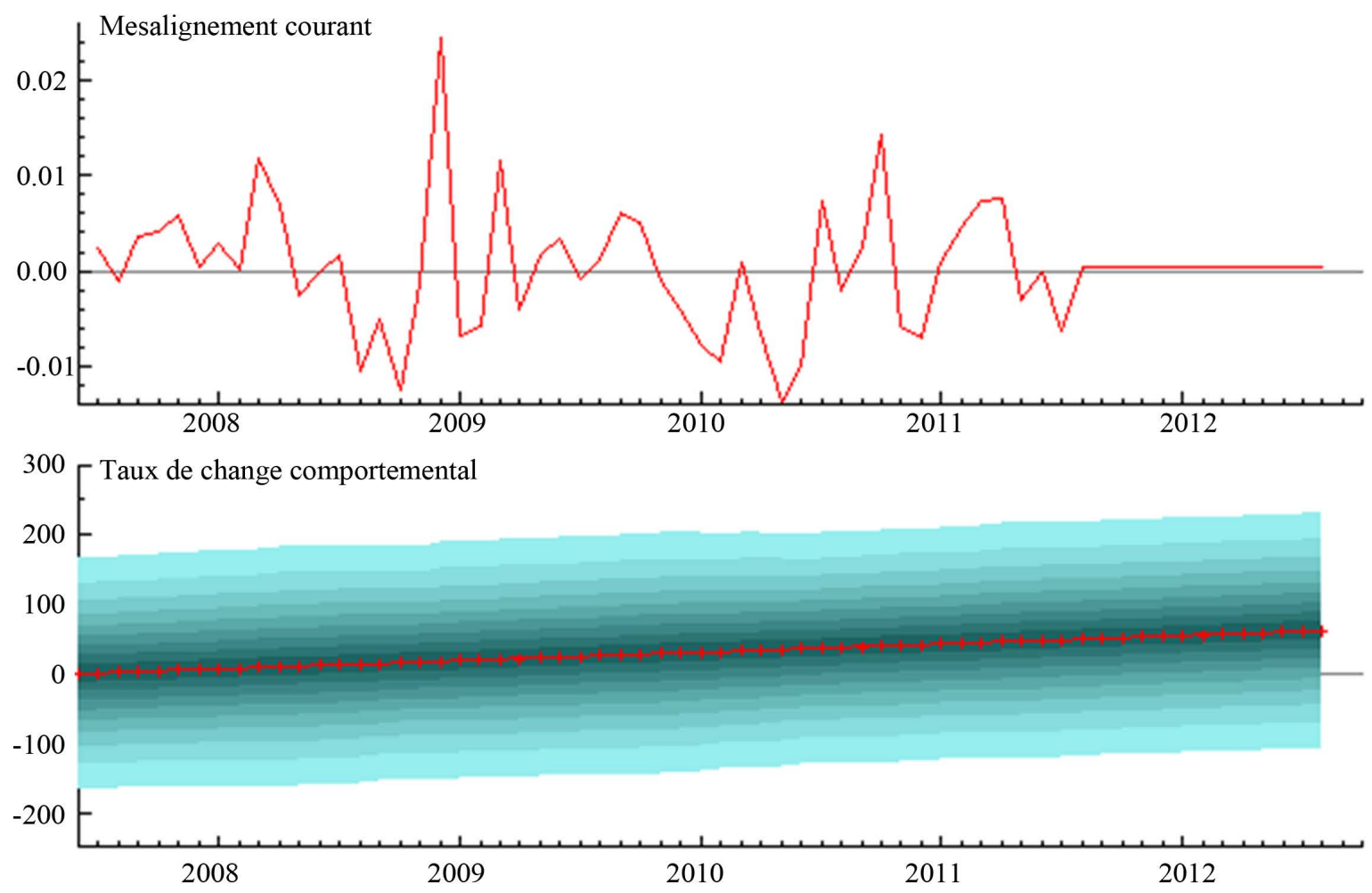

Figure 15. The case of Spain.
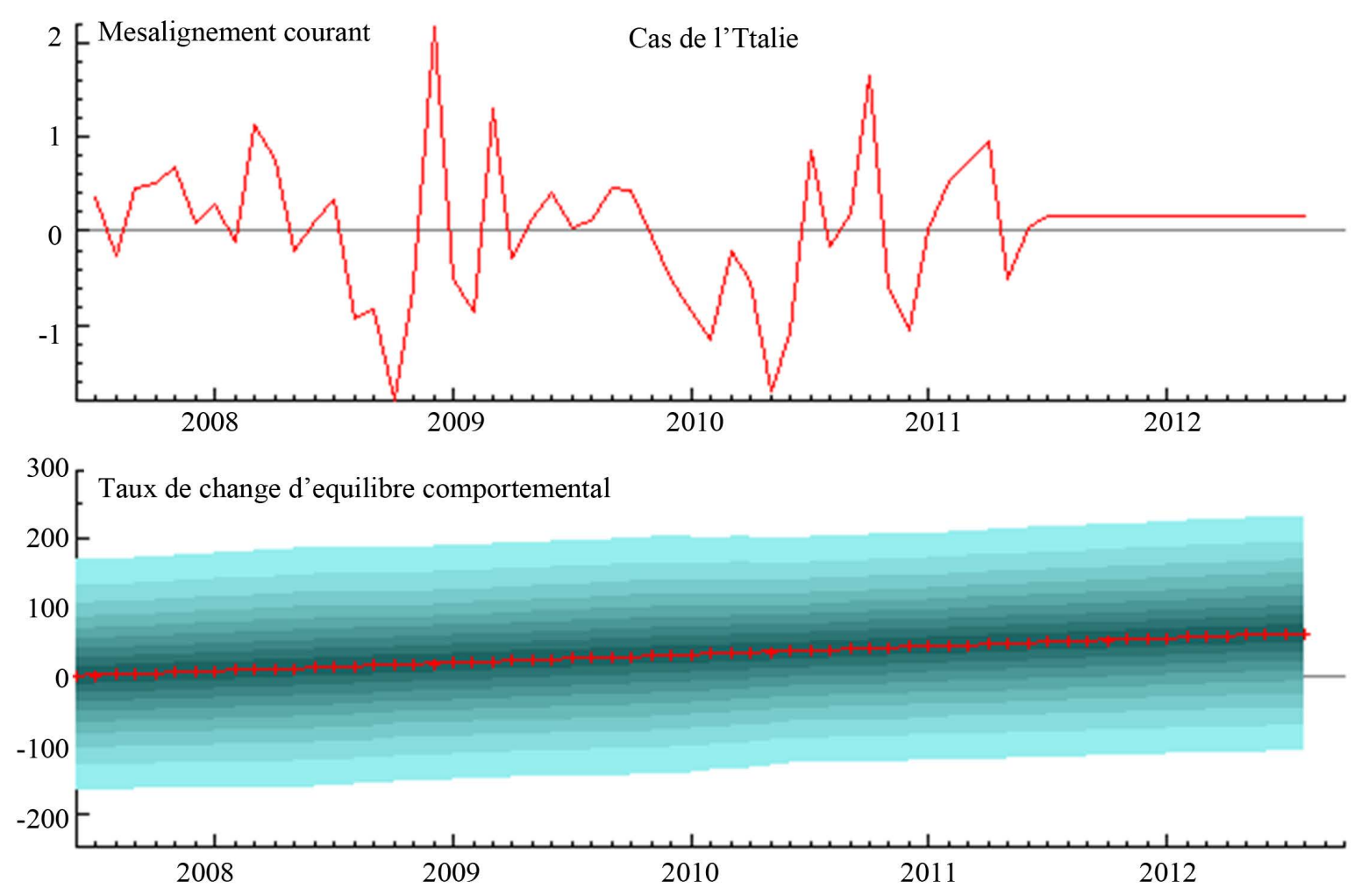

Figure 16. The case of Italy. 


\section{Appendix C: Concerning the Results of the Nonlinear Approach}
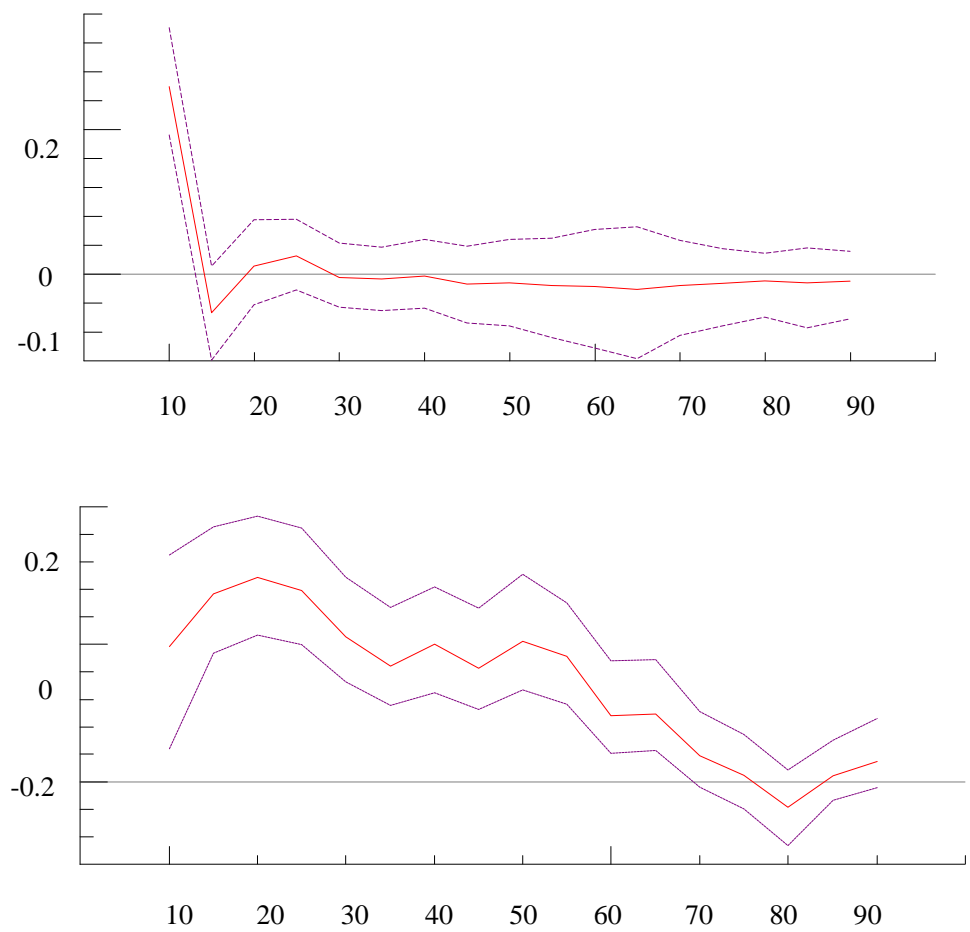

Figure 17. The responses of the output and inflation following a shock of monetary policy (in the case of Tunisia).
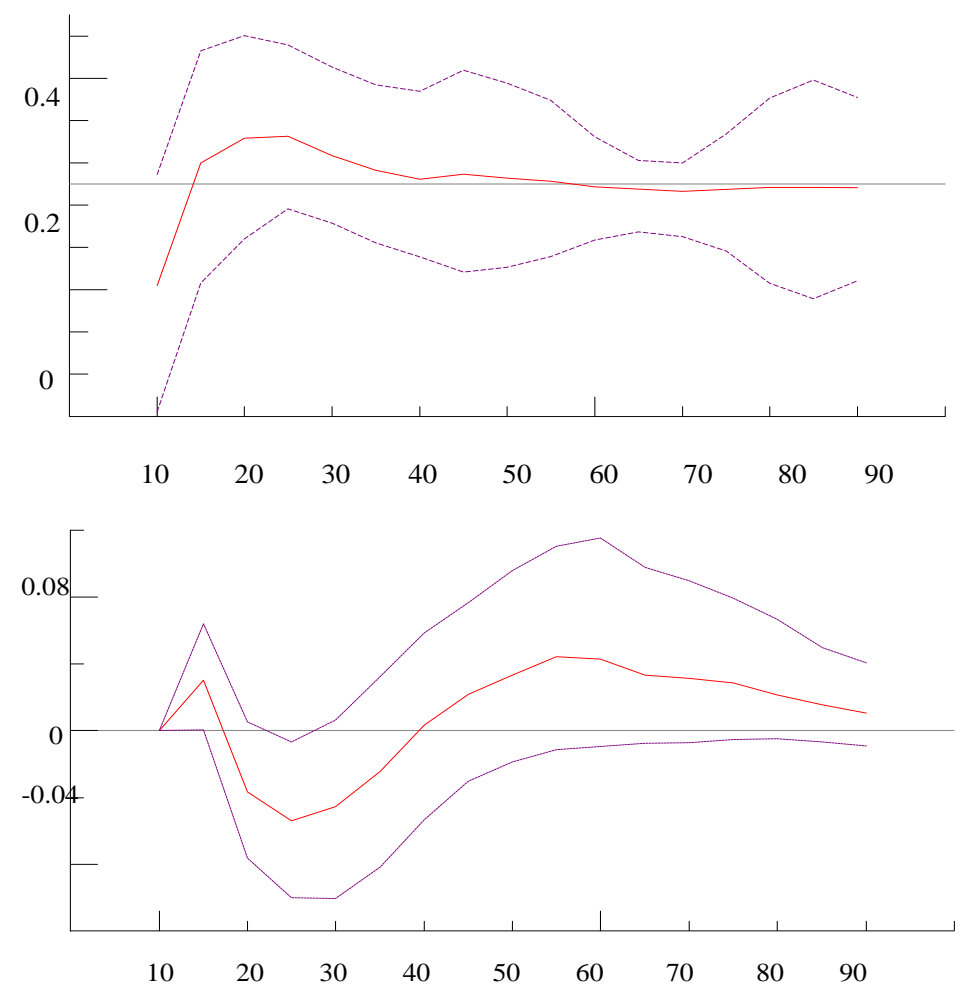

Figure 18. The responses of the output and inflation following a shock of monetary policy (in the case of the Egypt). 

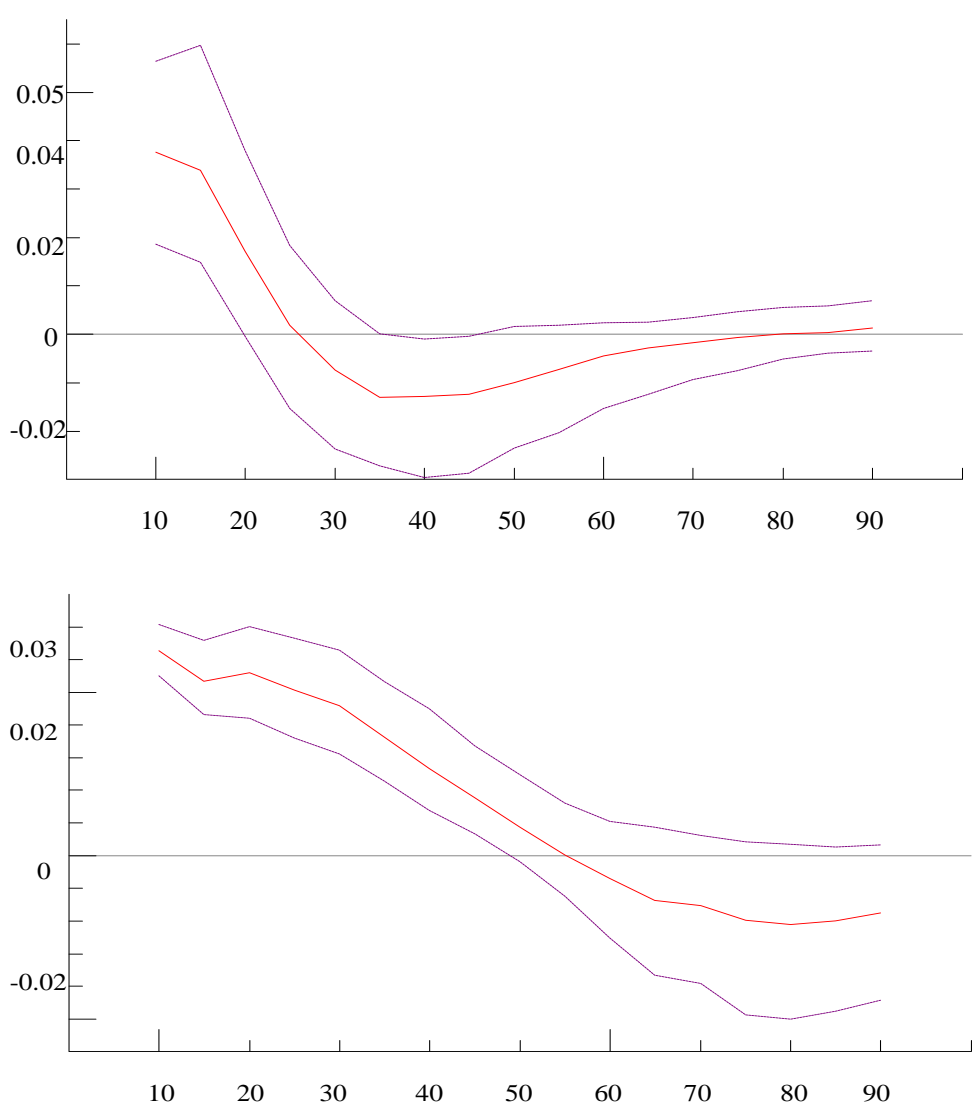

Figure 19. The responses of the output and inflation following a shock of monetary policy (in the case of Greece).
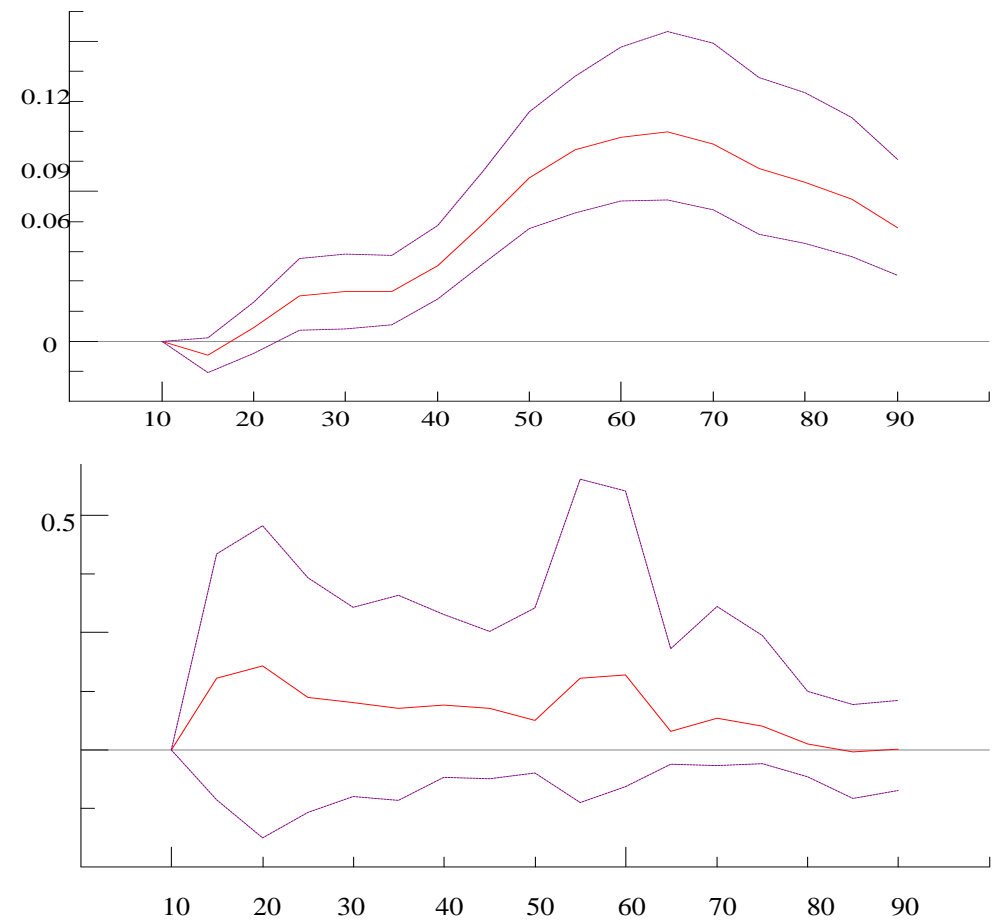

Figure 20. The responses of the output and inflation following a shock of the monetary policy (case of Portugal). 

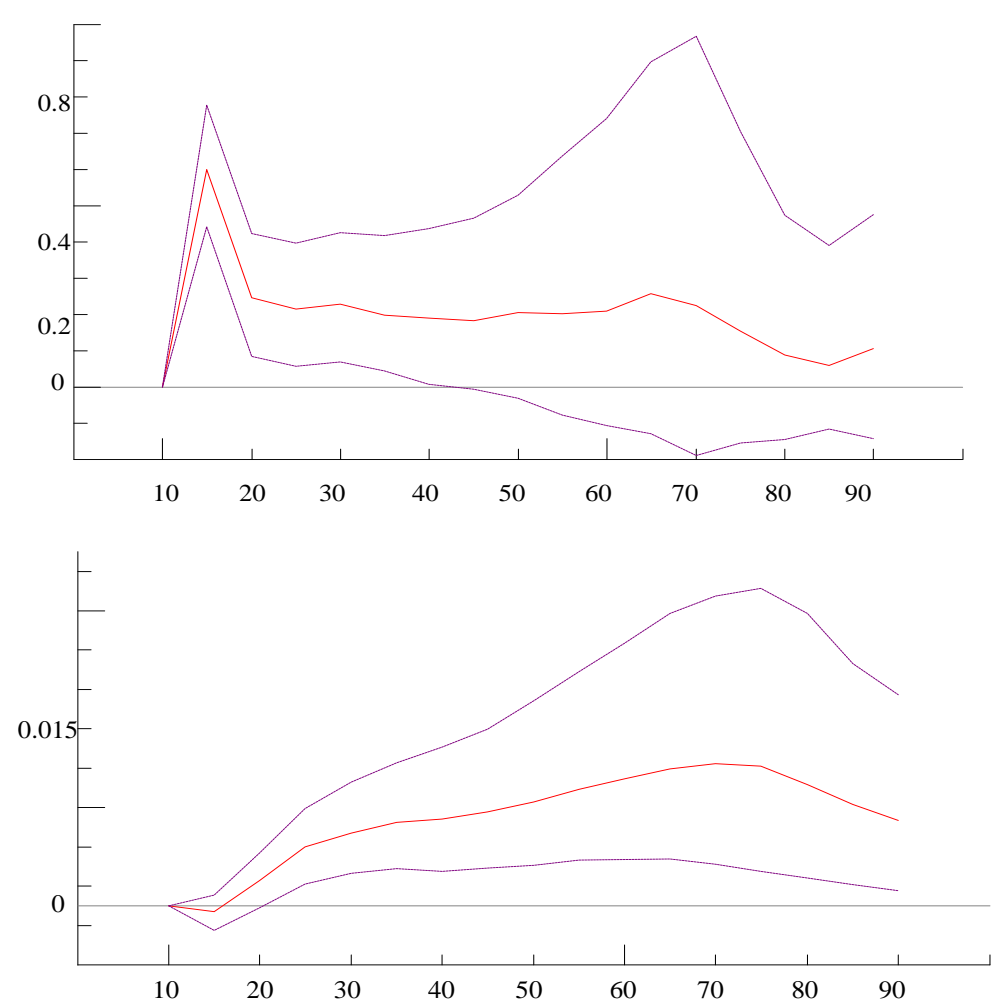

Figure 21. The responses of the output and inflation following a shock of monetary policy (Spain).
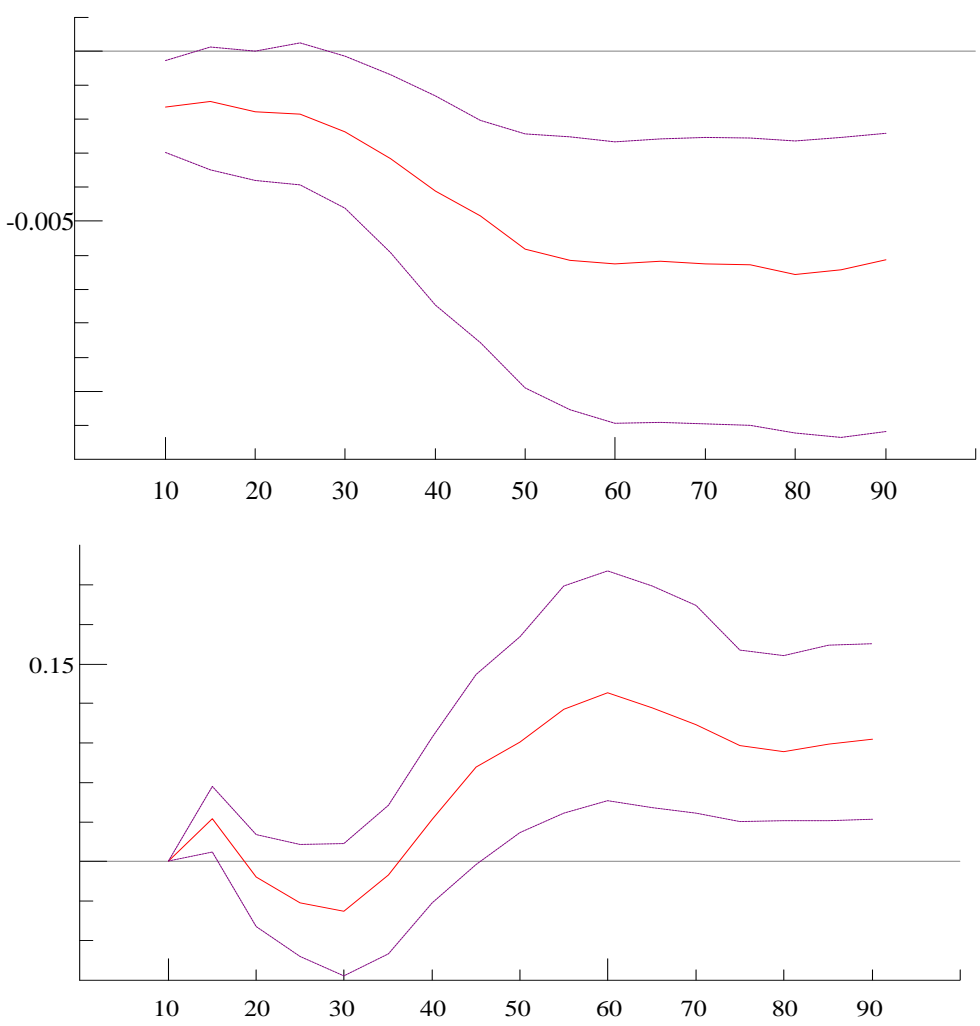

Figure 22. The responses of the output and inflation following a shock of the monetary policy (case of Italy). 